(Aus dem histologischen Laboratorium der Universität Charkow [Professor Kultschitzky].)

\title{
Einige Bemerkungen zur Morphologie und Entwickelung der Blutelemente.
}

\author{
Von
}

Dr. med. Gregorius Masslow.

Hierzu Tafel VIII u. IX.

\section{Methode.}

Bei meinen Studien wandte ich folgende Verfahren an:

1. Blutuntersuchung. Die Blutpräparate wurden nach der Ehrlich'schen Methode angefertigt: Trocknen bei $110^{\circ}$ bis $120^{\circ}$ C., Ueberfärbung der getrockneten Präparate; Auswaschen in Wasser und Alkohol; Aufhellen in Bergamottöl und Einschluss in Canadabalsan.

Ausser der Methode von Ehrlich wurde die Fixation nach $\mathrm{Nikif}$ orow angewandt: die an der Luft getrockneten Präparate wurden auf eine halbe Stunde in eine Mischung von gleichen Theilen Alkohol und Aether übertragen. Ausserdem wurden noch Snblimatlösung $(1 / 2 \%)$ und $\mathrm{K} \mathrm{ults} \mathrm{chitzky's}$ Flüssigkeit angewendet.

Von allen Fixirungsmethoden lieferte die besten Präparate die Ehrli c h'sche.

Die Methode von Nikiforow hat mir weniger befriedigende Resultate geliefert, da die Tinktion der Elemente hierbei nicht so deutlich auftrat, die Umrisse der Zellen und ihrer Kerne verschwommen blieben und die Kernstructur undeutlich erschien. Die anderen Fixirungsgemische besitzen den Mangel, dass bei ihrer Einwirkung in Plasma zahlreiche Niederschläge auftreten, welche die Farbstoffe aufnehmen und festhalten.

Zur Färbung dienten:

a) das Gemisch von sauren Farben nach E hrlich, 
b) die Färbung nach $\mathrm{R}$ i e d e $\mathrm{r}^{1}$ ),

c) von neutralen Farben beide Gemische von $\mathrm{Ehr}$ lich und die S pilli n g'sche Mischung,

d) die basische Farbemischung von Elr li e b.

2. Untersuchno der Organe. Beim Studium von Organen (Knochenmark, Lymphdrüsen und Milz) wurden folgende Fixirungsgemische angewandt : a) von Kults c h itzk y, b) Flemming, c) M üll e r, d) $1 / 2 \%$ Sublimatlösung, e) die von Löwit zur Differenzirung der einen und der anderen Art von Bildungszellen (Erythroblasten und Leukoblasten) in den blutbildenden Organen empfohlene $0,1-0,3 \%$ Platinchloridlösung.

Die besten Resultate lieferte die Flüssigkeit von Prof: $\mathrm{K}$ u l t s ch i t z ky: zu 50procentigem Spiritus wird im Ueberschuss Kali bichromic. und Cuprum sulfuric. hinzugefügt; die Mischung. wird 2-3 Tage im Dunkeln gelıalten, wobei die Salze allmählich in die Lösung übergchen; dann wird filtrirt und mit Essigsäure angesïnert (5-6 Tropfen Süure auf $100 \mathrm{ccm}$ Lösung); die Fixation geschieht im Dunkeln ${ }^{2}$ ).

Die in kleine Stücke zerschnittenen Organe wurden auf 5-10 Tage in diese Flitssigkeit gelegt. Hierbei wurde in einigen Fällen die Milz, bevor sie noch aus dem Thier entfernt war, mit derselben Flïssigkeit von der Arterie aus injicirt. Nach Beendigung der Injection wurden die zu- und abführenden Milzgefässe unterbunden und dann das ganze Organ 24-48 Stunden in das Gemisch gelegt, worauf behufs weiterer Fixation das Organ in kleine Stïcke zerlegt wurde. Die anf diese Art fixirten Stäckchen wurden in Alkohol $\left(98^{\circ}\right)$ übertragen; weiterhin folgte Aufhellung in Xylol und Einbettung in Parafin.

Fast gleich befriedigende Präparate lieferte die Flemmingsche Flüssigkeit, während die Objecte aus der Müller'schen Flüssigkeit weniger demonstrative waren.

Die Sublimatlösung und die Löw it'sche Lösung erwiesen sich gleicherweise als ungünstig.

Als die besten Farbencombinationen zeigten sich: Hämatoxylin und Aurantia, Hämatoxylin und Orange (G), Hämatoxylin zig 1893.

1) Rieder, Atlas der Klinischen Mikroskopie des Blutes. Leip-

2) Prof. N. Kultschitzky, Grundzüge der pralitischen Histologie. Charkow 1889 (russisch). 
und Rubin und Helianthin. Bei der Doppelfärbung wurden die Schnitte zuerst auf $1 / 4-1 / 2$ Stunde in Friedländer's Hämatoxylin gelegt, darauf in destillirtem Wasser ansgewaschen und dann in eine mit Essigsäure leicht angesäuerte gesüttigte Lösung von Aurantia oder Orange übertragen. Unter Einwirkung dieser Lösungen verlor sich der Ueberschuss von Hämatoxylin, an dessen Stelle die andern Farben traten, wobei sie alles, ausser den Kernchromatin tingirten; letzteres hehält selır gut das Hämatoxylin. Der Ueberschuss von Aurantia and Orange wurde durch schnelle Auswaschung der Schnitte in Alkohol entfernt. Es folgte die Aufhellung in Bergamottöl, der Einschluss in Canadabalsam.

Bei der dreifachen Färbung wurden die Schnitte anfangs mit Hämatoxylin gefälrbt $\left(1 / t_{-}-1 / 2\right.$ Stunde); nach Auswaschen in destillirtem Wasser kamen sie für dieselbe Zeit in eine mit Essigsäure angesäucrte $1 / 4 \%$ wässrige Rubinlösung. Die in Rubin überfärbten Präparate wurden nach der zweiten Auswaschung in Wasser ungefähr auf $1 / 4$ Stunde (zuveilen kürzere Zeit) in ebenfalls mit Essigsäurc angesäuerte wässrige Helianthinlösung gebracht. In letzterer Lösung wird der Rubinüberschuss extrahirt. Ferner entferut man den Ueberschuss von Helianthin durch Alkohol; Aufhellung und Einschluss wie oben. Die Kerne sänmtlicher Zellen erscheinen blau, die liämoglobinhaltigen Elemente (die kernlosen und nicht immer die kernhaltigen rothen Blutkörperchen - letztere sind meistentheils schwach tingirt -) sind durch Rubin roth; alles iibrige, das Protoplasma sowohl der Leukocyten als auch der Erythrocyten, die ihr Hämoglobin verloren haben, sind durch Helianthin gelb grefärbt. Diese dreifach combinirte Färbung wird schon seit langer Zeit von Prof. Kultschitzky für verschiedene Zwecke verwendet.

\section{Die farblosen Blutkörperchen.}

Wir können folgende morphologisch scharf gesonderte Gruppen von farblosen Elementen des normalen Blutes aufstellen:

In Betreff der Grösse zerfallen die in Rede stehenden Elemente in zwei grosse Gruppen: I. Gruppe der L y m p h o c y ten ${ }^{\mathbf{1}}$ ),

1) Die Benennung "Lymphocyten" passt eigentlich nicht vollkommen zu den Elementen dieser Gruppe, da sie sich nicht ausschliesslich nur in den Lymphdrüsen entwickeln. 
zu welcher Körperchen von verhältnissmässig geringer Grösse gehören, und II. Gruppe der eigentlichen Le uk o cy ten, welche alle übrigen farblosen Blutkörperchen umfasst; letztere unterscheiden sich von den oben erwähnten unter Anderem noch durch ihre bedeutendere Grösse.

Die I. Gruppe zerfällt ihrerseits in A) Gruppe $\mathrm{kl}$ e i n er Lymphocyten und B) Gruppe grosser Lymphocyten.

A. Die $\mathrm{kl}$ leine $\mathrm{n} \mathrm{L} y \mathrm{mp}$ h o e y te $\mathrm{n}$ sind Körperchen von sphärischer Form. Sie charakterisiren sich durch ihre geringe Grösse, die die Dimensionen der Erythrocyten nicht übertrifft oder sogar den letzteren etwas nachsteht; sie besitzen einen meistens vollkommen regelmässigen, runden Kern, der scharf contourirt ist und sich mit Hämatoxylin und anderen Kernfarben intensiv färben lässt; weit seltener hat der Kern eine schwach ausgesprochene elliptische Form, und zuweilen ist an seiner Peripherie eine kaum bemerkbare Einbuchtung zu beobachten. Im Allgemeinen sind die in Rede stehenden Elemente sehr arm an Protoplasma; manchmal ist letzteres in so geringer Menge vertreten, dass der Kern wie nackt erscheint; in der Mehrzahl jedoch bildet das Protoplasma einen schmalen Saum um den Kern, entweder von gleichmässiger Breite (der Kern liegt im Centrum des Zellleibes), oder von ungleichmässiger Breite (der Kern liegt excentrisch). An ausgetrockneten und gefärbten Präparaten ist es unmöglich, im Protoplasma eine Körnung nachzuweisen.

B. Die grossen L y m phocyte n besitzen ebenfalls eine sphärische Form, unterscheiden sich von ersteren durch ihre die Dimensionen der Erythrocyten übertreffende Grösse und die grösseren Kerne. Die Kerne sind bald rund, bald länglich elliptisch; an der Peripherie des Kernes trifft man hier häufiger eine oft scharf gezeichnete Einbuchtung an; der Kern färbt sich intensiv. Die Elemente dieser Gruppe besitzen eine weit grössere Menge körnigen Protoplasmas. Manchmal nehmen diese grossen Lymphocyten nur sehr wenig Farbstoff an. In pathologischem Blute kann das Protoplasma der Lymphocyten, dem Anscheine nach, eosinophile (?) Körner enthalten, wie Waldstein ${ }^{1}$ ) be-

1) Waldstein, Beobachtungen an Leukocyten, sowie über einige therapeutische Versuche mit Pilocarpin u. s. w. Berliner klin. Wochenschrift, 1895, Nr. 18, S. 398. 
Einige Bemerkungen zur Morphologie und Entwickelung etc. 141

richtet; Letzterer hat ähnliche Elemente mit sehr feinen Körnern im Blute Diphtheriekranker gefunden.

Die II. Gruppe der L e a k o c y te n besteht aus Elementen dreier Arten: C) einkernige Leukocyten mit einem mehr oder weniger legelmässig geformten Kerne, D) einkernige Le uk ocyten mit polymorphem Kerne und endlich E) vielkernige Le u k o y te n.

C. E i n k e r n i g e L e u k o c y t e n. Die Grösse derselben ist verschieden, übertrifft jedoch stets die der Lymphocyten. Der Kern ist verhältnissmässig gross, immer von mehr oder weniger oblonger, ovaler Form, selten besitzt er eine streng ovale Form; bei weitem häufiger bieten die Kerne dieser Leukocyten an der Peripherie deutliche Einbuchtungen (1-2) dar; sie färben sich nicht immer gleich intensiv, zuweilen nebmen die Kerne nur schwache Färbung an. Sowohl diese letzteren, als auch die obenerwähnten grossen Lymphocyten mit undeutlicher Structur entsprechen den Leukocytenschatten von $\mathrm{Kl}$ e in ${ }^{1}$ ), der sie für den Ausdruck eines beginnenden Absterbens hält. Die Leukocyten dieser Gruppe unterscheiden sich ferner durch eine grössere Menge Protoplasma, das gewöhnlich homogen erscheint. Jedoch kann ein Theil dieser Elemente auch im normalen Menschenblute granulirtes Protoplasma haben, wobei die Körnung läufiger eine basophile ist; manchmal aber treten im Zellleibe derselben die ersten Merkmale von neutrophilen Granula auf. Bei normalen Zuständen des Organismus enthält das Protoplasma der in Rede stehenden Art von einkernigen Leukocyten scheinbar keine eosinophilen Körner. Mir wenigstens ist es niemals gelungen, solche Formen zu beobachten, und bei keinem Autor sind irgend welche Andeutungen darüber zu finden. Unter pathologischen Verhältnissen aber kömnen solche Formen sowohl im Blute als auch in manchen Secreten angetroffen werden. Hierher gehören die Beobachtungen von Klein, wahrscheinlich auch diejenigen von Spilli $\mathrm{ng}^{2}$ ); derselbe fand im leukämischen Blute "kleinere und kleinste Formen" von eosinophilen Zellen. Letzterer traf ausserdem in demselben Blute einkernige Elemente mit einer

1) Klein, Die diagnostische Verwerthung der Leukocytose. Sammlung klinischer Vorträge. Leipzig 1893, Nr. 87.

2) Spilling, Ueber Blutuntersuchung bei Leukämie. Farbenanalyt. Unters. z. Histol. u. Klinik des Blutes. Inang.-Díss. Berlin 1891. 
Masse neutrophiler Grantla in ibrem Protoplasma an. Gabrits cbewsky fand viele einkernige eosinoplile Leukocyten im Sputum bei Bronchialastlima, wic das aus der seiner Arbeit bei gelegten Abbildung zu erselien ist.

Im Blute junger Thiere (Hunde) kommen normal in ziemlich grosser Menge cinkernigre (selten doppelkernige) Elemente vor, die sich von den iibrigen Körperchen durch ihre ungewöhnlich grossen Dimensionen scharf abhcben. Diese Elemente besitzen stets eine grosse Menge nicht g'ranulirten Protoplasmas und einen grossen ovalen Kern von guter Färbbarkeit. Für die Bildungsstätte diescr Körperchen wird gewöhnlich das Knochenmark gehalten. Im Menschenblute kommen die genannten Gebilde nur in pathologischen Fällen vor, so z. B. bei myelogener Leukämie; ilı Protoplasma enthält dann oft eine eosinophile, seltener eine neutrophile Körnung.

D. Die polymorphkernigen Leukocyten unterscheiden sich, wie auch die übrigen Elemente dieser Art, von den Lymphocyten durch ihre bedeutende Grösse. Höchst charakteristische Eigenschaften zum Unterschied von den übrigen Leukocyten bieten ihre Kerne dar, welche entweder in Gestalt verschiedenartig gekrümmter wurstförmiger Bildungen erscheinen, wobei die Kernform oft an Buchstaben erinnert - $O$ (gelöcherte Form), U, V, S, C u. s. w., oder der Kern bildet eine complicirtere, aus inehreren verschieden grossen Theilen bestehende Figur, dieselben sind verbunden mittelst mehr oder weniger dünner Fäden, die gleich der Kernsubstanz die gewöhnlichen Kernfarben gierig anfnehmen. Anf dem dunklen Grunde der intensiv tingirten Kernfigur beobachtet man intensiver gefärbte, dünne oder dicke fädenartige Bildungen, deren Verbindung ein mehr oder weniger grobes Kernnetz vorstellt. Uebrigens findet man unter diesen Körperchen auch solche, deren Kerne schwach gefärbt sind und keine netzälnnliche Structur aufweisen; sie erscheinen wie aufgequollen, verwischt.

Die polymorphkernigen Leukocyten sind hauptsächlich die Träger der neutrophilen Körnung; seltener enthält ihr Protoplasma eosinophile Körner; häufig ist es auch homogen.

Im normalen Blute beobachtet man unter den in Rede stehenden körnigen Elementen dann und wann Körperchen, welche ihrem Charakter nach den Lenkocytenschatten von Klein ent- 
Einige Bemerkungen zur Morphologie und Entwickelung etc. 143

sprechen. Das sind Elemente mit sehr blassem, kaum sichtbaren Protoplasma, dessen Umrisse sehr undentlich sind; im Protoplasma befinden sich spärliche Granula; dieselben werden häufig: in grösserer oder geringerer Anzahl auch in der Umgebung des Körperchens angetroffen; ihre Kerne sind sehr schwach gefärbt und homogen, ohne jegliche Zeichen einer Differenzirung der Chromatinsubstanz.

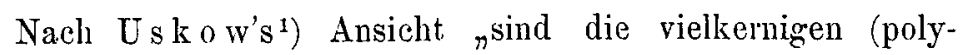
morphkernige und eigentlich vielkernige) weissen Blutkörperchen das älteste lebensfähige Zellelement des Blutes mit den Zeichen einer beginnenden regressiven Metamorphose in ihrem Vermehrungsorgane".

D e k h y z e ${ }^{2}$ ) meint, dass die polymorphkernigen und polymerkernigen Leukocyten einen normalen erwachsénen Znstand, aber kein Degenerationsstadium vorstellen. Die Tendenz des Leukocytenkernes zur Polymerie sei nicht als der Ausdruck eines beginnenden Absterbens der Zellen aufzufassen, sondern als ein physiologischer Vorgang bei der Erreichung des erwachsenen Zustandes.

Ebenso weisen auch Flemming's ${ }^{3}$ ) Beobachtungen iiber Mitosen an polymorphen Kernen darauf hin, dass die Kerne vollkommen lebensfähig sind und sich vermehren können.

E. Die eigentlichen vielkernigen Leukocyten besitzen alle Eigenschaften der Elemente der vorigen Art, sowohl in Bezug auf Grösse der Körperchen, als auch im Sinne des Charakters ibres Protoplasmas (körnigen oder homogenen). Das einzige Charakteristicum besteht in dem Vorhandensein zweier oder mehrerer vollkommen isolirter Kerne, welche mit einander nicht verbunden sind. Auch hier begegnet man schwach tingirten Kernen mit nur undeutlich ausgeprägter Struktur. Vielkernige Leukocyten sind im Blute nur in sehr geringer Anzahl vertreten.

Nach $\mathrm{H}$ ow el l's Ansicht entstehen die polynucleären Ele-

1) Uskow, Blut als Gewebe. St. Petersb. 1890 (russisch).

2) Dekhuyzen, Ueber das Blut der Amphibien. Anatomischer Anzeiger. 1892.

3) Flemming, Ueber Theilung und Kernformen bei Leukocyteu und über deren Attractionssphären. Arch. f. mikr. Anatomie, Bd. $37,1891$. 
mente aus den polymorphkernigen durch Kernfragmentation, nach welcher wahrscheinlich der Zerfall der ganzen Zelle stattfindet. Flemming erklärt ebenfalls das Vorkommen von mehreren Kernen in den Leukocyten. durch eine Kernfragmentation, wobei er die letztere als einen Process ansielt, der nicht zur physiologischen Vermelurung der Zellen führt. Deshalb sind die auf diesem Wege entstandenen Elemente zur Reproduction nicht fähig, sondern eher zum Absterben bestimmt, wenngleich sie noch sehr lange in den Geweben und Säften des Organismus leben könnten.

Nach $\mathrm{K} \ddot{o l l i k e r}$ ist der Uebergang der Lymphkörperchen zu polynucleären Formen die Folge eines Zerfalls des einfachen Kernes, der den Zerfall der ganzen Zelle einleitet.

Lö $\mathrm{wit}^{1}$ ) glaubt ebenfalls, dass die mononucleären Zellen, aus den blutbildenden Organen ins Blut gelangend, hier eine ganze Reibe von degenerativen Veränderungen erleiden, die nicht zur Neubildung von Kernen oder Zellen führen. Hier geschehe einfach ein Zerfall des Kernes in mehrere Fragmente, zu welchem später wahrscheinlich auch der Zerfall der ganzen Zelle hinzutrete.

Gleicherweise hält auch $\mathrm{M} u ̈ 1 \mathrm{le} \mathrm{r}^{2}$ ) die polynuclären und polymorphkernigen Leukocyten nicht für selbständige Zellformen, sondern nur für den Ausdruck eines zeitweiligen Zustandes einer und derselben Zellenart, der sich noch weiter verwandeln könne.

Was den genetischen Zusammenhang sämmtlicher besprochener Leukocytenformen anbelangt, so ist $\mathrm{zu}$ bemerken, dass wir, ungeachtet der scheinbaren scharfen Isolirung einzelner Arten, eine nahe Verwandtschaft zwischen ihnen annehmen müssen, da viele unbestreitbare Thatsachen mit grosser Wahrscheinlichkeit für die Umwandlung der einfachsten Arten in complicirtere sprechen, wie das auch heutigen Tages von vielen Autoren (Dekhuyzen, Flemming, Gulland, Uskow, Howell, M ü ll e r, Bi ondi etc.) anerkannt wird. So sind nach

1) Löwit, Ueber Neubildung u. Zerfall weisser Blutkörperchen. Ein Beitrag zur Lehre von der Leukämie. Sitzungsber. der Wiener Akademie, Bd. 92, Abth. 3, 1885.

2) Müller, Zur Frage der Blutbildung. Sitzungsber. d. Wiener Akademie, Bd. 98; Abth. III, Heft VI, 1889. 
Einige Bemerkungen zur Morphologie und Entwickelung etc. 145

Bi on $\mathrm{di}^{1}$ ) die verschiedenen farblosen Blutkörperchen - monound polynucleäre, fein- und grobkörnige - nur Entwickelinngsstadien einer und derselben Zellform.

Für die Umwandlung spricht die Thatsache des Vorhandenseins von Uebergangsformen zwischen kleinen Lymphocyten (A) und mononucleären Leukocyten (C) im Blute und in den blutbildenden Organen. Als solche Uebergangsformen kann die Gruppe der grossen Lymphocyten (B) gelten, die die Mitte zwischen beiden genannten Zellarten einnehmen, sowohl nach der Grösse der Körperchen selbst, als auch nach der Menge des Protoplasmas und der Grösse ihrer Kerne.

Weiterhin spricht für den Uebergang der Lymphocyten in Leukocyten noch jener Umstand, dass die Kerne der-ersteren häufig mit einer Einbuchtung (die Andentung eines späterèn Polymorphismus des Leukocytenkernes) versehen sind.

Endlich wird die nabe Verwandtschaft der in Rede stehenden Formen noch durch die vollkommene Identität der Lymphdrüsenelemente mit den jüngsten Elementen der $M$ alpighischen Körperchen der Milz bestätigt. Die Malpighi'schen Körperchen bieten eben das am schärfsten ausgeprägte Bild einer allmählichen Verwandlung der sehr kleinen mononucleären Zellen mit relativ grossem Kern and geringer Menge Protoplasma (Aehnlichkeit von kleinen Lymphocyten des Blutes und andererseits von der Mehrzahl der Elemente der Lymphfollikel) in mononucleäre Elemente, welche sich durch ihre grossen Kerne und ihre grosse Menge Protoplasma auszeichnen (Aehnlichkeit mit mononucleären Lenkocyten).

Der Tebergang der mononucleären Leukocyten zu den polynuclären stellen die mononuclären Formen vor, deren Kern mit einer Einbuchtung versehen ist. In Folge der Vergrösserung der aufangs schwach ausgesprochenen Einbuchtung kommt der bufeisenförmige, wurstähnliche Kern zu Stande. Dieser letztere, sich vielfach krümmend, kann die bizarrsten Formen annehmen. Die Entstehung dieser letzteren könnte theilweise durch die amöboide Bewegung der Leukocyten erklärt werden (Gulland, Jegorowsky).

1) Biondi, Untersuchungen iiber, d. weissen Blutkörperchen bei Leukämie. Refer. Berlin. klin. Woch. Nr. 29, 1895.

Archiv f. mikrosk. Anat. Bd. 51 
Es giebt aber Beobachtungen, die Veranlassung geben, dem Kerne die Fähigkeit zu selbständigen Bewegungen zuzuselureiben. Für die Selbständigkicit dieser Bewegungen sprieht theilweise jener Umstand, dass die polymorphen Kernfiguren häufig auch in solchen Körperchen (des Blutes und der Organe) vorkommen, deren protoplasmatischer Zellleib die regelmässigen Umrisse behalten hat und keine Zeichen der Veränderung seiner Configuration darbietet.

$\mathrm{Zu}$ Gunsten der erwähnten Vermuthung sprechen ebenfalls die directen Beobachtungen über die Kernbewegungen der farblosen und rothen Blutkörperchen.

So will ich nur an die bekannten Beobachtungen von Brand ${ }^{1}$ ), Maragliano und Castellin ${ }^{2}$ ), Lavdowsk ${ }^{3}$ ) und $M$ ü $l l$ er erinnern.

Weiterhin lässt F I e m m in $\mathrm{g}^{4}$ ) die Möglichkeit der Bildung von durchlöcherten, ringförmigen Kernen aus mitotischen Theilungsfiguren zu.

Gegenüber der Ansicht $\mathrm{R}$ a th's, der die erwälınte Mitosenform für anormal und die auf diese Weise entstandenen Kerne unfähig: zur weiteren Theilung hält, erkennt sie F lem ming als vollkommen normal an, da sich nacb seiner Weinung solche Kerne wieder mitotisch theilen können.

Fòlglich bilden sich aus den mononucleären Leukocyten mit einfachem (rundem) Kerne polymorphnucleäre Formen mit einem complicirten Kerne, und aus diesen letzteren entstehen dann die polynucleären Elemente, wie oben gesagt worden ist.

Von den verschiedenen Klassificirungen der farblosen Elemente sind nur diejenigen beachtenswerth, als die am meisten

1) Brandt, Bemerkungen über die Kerne der rothen Blutkörperchen. Arch. f. mikr. Anat., Bd. XIII, 1877.

2) Maragliano und Castellino, Ueber die langsame Nekrobiosis der rothen Blutkörperchen sowohl in normalem wie auch in pathologischem Zustande u.s.w. Zeitschr. f. klin. Medic., Bd. XXI, Heft 5 u. 6.

3) Lav d ow sky, Mikroskopische Untersuchungen einiger Lebensvorgänge des Blutes. Vir ch ow's Arch., Bd. 96-97, 1884-1885.

4) Flemming, Zelltheilung. Amitose und besondere Formen der Kerntheilung. Ergebnisse der Anatomie u. Entwicklung'sgeschichte, Bd. III, 1894. 
Einige Bemerkungen zur Morphologie und Entwickelung etc. 147

rationellen, $z \mathfrak{u}$ deren Grundlage beständige und unveränderliche Merkmale verwendet sind, wie das die typischen morphologischen Eigenschaften einzelner Arten darbieten. In dieser Hinsicht müssen in erster Reihe die charakteristischen Unterschiede der Kerne genannt werden, d. L. ihre Form, Grösse, ihre Menge und weiterhin die Grösse des Körperchens selbst, das gegenseitige Verhältniss der Grösse des Kernes zur Protoplasmamenge, der Charakter dieses letzteren (Körnung). Nur alle diese Merkmale, zusammengenommen, erlauben, uns in dieser auf den ersten Blick so bunten Mannigfaltigkeit der farblosen Blutkörperchen zurechtzufinden. Deshalb kann ich auch den Versuch nicht für rationell halten, sämmtliche mannigfaltigen Leukocytenformen auf Grund irgend eines Merkmals zu sondern, wie das früher Wharto u Jone $\mathrm{s}^{1}$ ) in Bezug auf die Protoplasmakörnung und in neuester Zeit L a v dowsky gethan haben, umsomebr, da auch die Granula, wie es sich erwiesen hat, nicht allein Grössenverschiedenheiten darbieten. Andererseits compliciren manche Forscher bedeutend die in Rede stehende Klassifikation, indem sie solche Arten sondern, die nur als Varietät schon bekannter Formen erscheinen (so z. B. die Leukocytenschatten von Klein).

Eine solche z. B. ist die complicirte Gruppirung der farbIosen Blutelemente von Uskow, die auf vermeintlichen Reifestadien der Blutelemente begründet ist, die ich jedoch als eine berechtigte und zu empfehlende nicht anerkennen kann.

Wie bekannt, hat $\mathrm{Ehr} / \mathrm{i} \mathrm{h}^{2}$ ), indem er bei seinen Studien die Anilinfarben anwandte, uns ein vollkommen neues Princip behufs Unterscheidung der cinzelnen Arten von farblosen Blutelementen geliefert. Er hat bemerkt, dass die in ihrem Zellleibe vorkommende Körnung für jede Leukocytenart charakteristische Eigenschaften besitzt.

Er unterscheidet drei Grundarten von Körnung der farblosen Blutelemente: 1. die acidophile (eosinophile), die nur saure Anilinfarben aufnimnt, 2. die basophile, welche sich durch ba-

1) Wharton Jones, The Blood-corpuscle considered in its diffe. rent Phases of Development in the Animal Series. I. Vertebrata. II. Invertebrata. Philosophical Transaction, 1845.

2) Ehrlich, Ueber die specifischen Granulationen des Blutes. Farbenanalyt.Untersuch. zur Histologie u. Klínik des Blutes. Berlin 1891. 
sische Farben tingiren lässt, und 3. die neutrophile Körnung, die die Fähigkeit besitzt, ausschliesslich eine neutrale Farblösung: im Sinne Ehrlich's aufzunehmen und die folglich eine gemischte Färbung annimmt, deren Nüancen jedoch in weiten Grenzen variirt, theils in Abhängigkeit von der Zusammensetzung des Farbengemisches, theils aber von Bedingungen, welche bis jetzt noch unbekannt sind.

Ehrlich gegenüber behauptet Rieder ${ }^{1}$ ), ibm sei gelungen, die Anwesenheit von mononucleären und polynucleären neutrophilen Zellen im Blute einiger Thiere (Kaniuchen, Meerschweinchen) zu beweisen, sowohl bei normalen Thieren als auch bei künstlich hervorgerufener Leukocytose durch Einführung: von bakteriellen Giften (Pyocyaninprotein) in das Blut. In beiden Fällen war die Anzahl der erwähnten Zellen keine bedeutende.

In Uebereinstimmung mit $\mathrm{R}$ i e d e $\mathrm{r}$ gelang es mir, bei einigen scheinbar vollkommen gesunden Thierarten im Blute eine kleine Menge von neutrophilen Leukocyten zu finden. In allen Fällen wurde das Blut nach Ehrlich's Methode fixirt. Ich fand solche bei mehreren Meerschweinchen, ebenso im Katerblut, wo die neutrale Farblösung (saures Fuchsin+Methylenblau) eine grosse Menge Leukocyten, die im Protoplasma eine Masse von Granula enthalten, welche bald deutlich violett, bald rötblichviolett tingirt sind, zeigte; die Körner besassen gewöhnlich eine gleiche Grösse. Auch bei jungen Hühnchen und beim Wespenfalken sah ich neutrophile Leukocyten.

Nicht alle Autoren übrigens stimmen mit der Ansicht Ehrlich's über die Specifität der Leukocytengranula ïberein. Griesbach ${ }^{2}$ ) stellt sogar die Existenz der Leukocytenkörnung als solche ganz in Abrede und hält das körnige Anssehen für den optischen Ausdruck eines besonderen Baues des Protoplasmas.

1) Rieder, Beiträge zur Kenntniss der Leukocytose und verwandter Zustände des Blutes. Leipzig 1892.

2) Griesbach, Beiträge zur Kenntniss des Blutes. Ueber die amöboiden Zellen des Blutes und ihre Betheiligung an der Gerinuung desselben. Arch. f. d. gesammt. Physiologie, Bd. 50, H. IX-X, 1891. Derselbe, Ueber die normale Gestalt und die Gestaltverïnderungen der Leukocyten des Blutes von Wirbellosen und Wirbelthieren. Verhandlung. des X. internat. med. Congresses, Bd. II, Abth. 1, Anat, 1891. 
Einige Bemerkungen zur Morphologie und Entwickelung etc. 149

Er unterscheidet im Zellkörper zwei verschiedene Substanzen -. die Gerüstsubstanz oder Spongiosa und die Zwischensubstanz.

Partikelchen der Geruistsubstanz und der Zwischensubstanz können sich abschnüren; die auf solche Art entstandenen körnerähnlichen Bildungen, aus dem Zellkörper in die Umgebung gelangend, können aus der Zelle ausgetretene Körner vortäuschen. Jedoch ist es nach Griesbach möglich, an diesen körnerähnlichen Gebilden doppelte Contouren nachzuweisen, welcher Umstand nach dem Autor auf combinirte Abschnïrung eines Stückchens von der Zwischensubstanz mit einem dasselbe umgebenden und in Zusammenlang gebliebenen ringförmigen Theilchen losgerissener Geriustsubstanz hinweist.

Der Ansicht G ri e s b a ch's widersprechen jedoch folgende Umstände. Die Lenkocytengranula haben stets eine regelmässige Form, die Umrisse sind glatt, ohne Unebenheiten, wobei die Regelmässigkeit der Form sowohl an Körnern, die in der Zelle enthalten sind, als auch an denjenigen, welche aus derselben in die Umgebung ausgetreten sind, anffällt. Betrachtet man aber die der Griesbach'schen Arbeit beigelegten Abbildungen, so springt sofort in die Augen die auffallende Unregelmässigkeit, die eckigen Umrisse der von ihm gezeichneten falschen Granula. Zweitens gelingt es niemals, an echten Körnern eine Doppelcontourirung ihres peripherischen Theiles zu constatiren. Endlich ist die Körnung kein beständiger und unveränderlicher Bestandtheil des Leukocytenprotoplasmas.

A l tmann ${ }^{1}$ ) hat bekanntlich behauptet, dass die Granula a 11 e n Zellen zukämen, somit nichts für die Leukocyten besonderes seien. Indessen hatte auch Altmann Fälle, wo es ihm nicht gelang, irgend welche Körnung nachzuweisen, wenn „der Zellleib trotz sorgfältiger Differenzirung mit Picrin gleichmässig roth blieb und bei übermässiger Differenzirung gleichmässig farblos wurde; es war demnach nicht $\mathrm{zu}$ entscheiden, ob es sich hier um eine gleichartige Substanz oder um so kleine und dichte Granula handelte, dass dieselben mit den heutigen Objectiven nicht mehr aufgelöst werden können".

Letztere Vermuthung ist offenbar hervorgerufen worden durch das Bestreben, der Granulalehre allgemeine Geltung zu erhalten.

1) Altmann, Die Elementarorganismen und ihre Beziehung zu den Zellen. Leipzig 1890. 
Auch im Blute kommen "sicher körnchenfreie Zellen" vor, wie Ehrlich richtig bemerkt.

Wie müssen wir nun aber die Körnung ansehen? Sind wir berechtigt, dieselbe als eine specifische, dem Leukocytenkürper eigene Bildung zu betrachten, deren Herkunft auf die Lebensthätigkeit dieser let»teren zurückzuführen ist, odler stellen im Gegentheil die Granula dem Leukocytenkörper fremde Bildungen vor, welche von den Leukocyten von aussen her aufgenommen sind? Das ist z. B. Hoy er's Ansicht über die Herkunft der eosinophilen Granula in Folge dessen, dass Brnchstücke von zerfallenen Erythrocyten oder Hämoglobin durch farblose Blutzellen aufgenommen worden seien.

Die bisher gewounenen Thatsachen scheinen eher zu Gunsten der ersten Vermutbung zu sprechen. In dieser Hinsicht verdient die Granulaform eingehender betrachtet zu werden, da namentlich in den Leukocyten eigenthümliche Formen dieser Gebilde gefunden sind, die in keinen anderen Zellen vorkommen. Wenigstens beobachtet man bei manchen Thierarten (Vögeln) ausser sphärischen noch Grannla von kurzer Stäbchenform mit abgerundeten Enden (Eh.rlich); ausserdem sind im Blute und Knochenmarke der Vögel Elemente mit ovalen Körnern (B i z z ozero und Torre ${ }^{1}$ ) aufgefunden worden; endlich giebt es Granula in Form einer an beiden Enden zugespitzten Spindel, welche im Centrum einen runden ungefärbten Punkt besitzt (Bizzozero ${ }^{2}$ )). Bizzozero erwähnt jedoch nur flüchtig dieser letztgenannten eigentbümlichen intracellulären Bildungen.

Mir gelang es, die soeben erwähnte Art von Körnung im Vogelblute (Hühnchen) zu beobachten. Hier trifft man ausser den Leukocyten mit gewöhnlichen runden Granula eine grosse Menge von Elementen, deren Zellleib mit stäbchenförmigen Körnern dicht gefüllt ist. Besonders demonstrative Bilder erhielt ich an Präparaten, die nach $\mathrm{Ehrlich}$ 's Methode fixirt and mit neutralen Mischungen gefärbt waren.

Bei starken Vergrösserungen präsentiren sich die stäbchen-

1) Bizzozero und Torre, Ueber die Blutbildung bei Vögeln. Centralblatt f. d. medicin. Wissenschaft, 1880 , Nr. 40.

2) Bizzozero, Neue Untersuchungen über den Bau des Knochenmarks bei den Vögeln. Arch. f. mikr. Anat. 1890, Bd. 35. 
förmigen Körner in höchst verschiedener Form: bald erscheinen sie als feine, glatte Stäbchen mit abgerundeten Enden, bald als dickere und verhältnissmässig kurze eiförmige Bildungen; häufig findet man Körner, die das Aussehen von dicken, kurzen und regelmässigen ovalen oder schmäleren und längeren Spindeln mit zugespitzten, zuweilen bedeutend ausgezogenen Enden darbieten; nicht selten haben die Granula mehr bizarre Umrisse, an die Mondform oder die eines dicken Kommas erinnernd, in anderen Fällen ist ein $\mathrm{Pol}$ der Eifigur stark ausgezogen und zugespitzt u. s. w.

In der Substanz der dickeren Stäbchen unterseheidet man deutlich einen ganz hellen, ungefärbten runden Punkt, der auf dem dunklen Grunde des Körnchens scharf hervortritt (s. Taf. VIII, Fig. 2 u. 3). Der genannte Punkt ist gewöbnlich im centralen Theile des Körnchens gelegen, seltener ist er mehr oder weniger zu einem von den Polen der oblongen Bildung hin verschoben. Im letzteren Falle erscheint der betreffende Pol oft keulenförmig aufgetrieben, während bei centraler Lage des hellen Punktes nur selten der mittlere Theil des verlängerten Körnchens aufgetrieben ist. Mit dem erwähnten hellen Punkte ist die Mehrzahl der Körner versehen; indessen kommen auch Formen vor, die ganz homogen erscheinen und gleichförmig tingirt sind. Jedes stäbchenförmige Körnchen besitzt nur einen hellen Punkt, wobei die Grösse der Punkte eine sehr unbedentende und ziemlich constante ist.

Im Allgemeinen haben die Körner einer und derselben Zelle eine fast gleiche Grösse und ungefähr gleiche Form; bäufig aber werden auch solche Elemente angetroffen, deren Körner ziemlich versehieden sind: neben dünnen, langen und geraden Stäbchen findet man mehr oder weniger gekürzte, dicke Körner, die sich. der Form nach bald einem Oval, bald einer Ellipse oder einem Kreise nähern.

Zuweilen werden einzelne Körner aus dem Leukocytenkörper hinausgestossen und liegen frei in der Nachbarschaft desselben. Der Zellleib solcher Leukocyten ist gewöhnlich undeutlich ausgeprägt, wie verwischt; seine Umrisse sind vollkommen unsichtbar.

Neben diesen, scheinbar zerfallenden Lenkocyten erblickt man Elemente mit ziemlich scharf contourirtem protoplasmatischen 
Leibe von unregelmässiger Form; in demselben sind grosse Granula enthalten, welche intensiv dunkel violett gefärbt erscheinen. Ein Theil der Granula zeigt einen centralen hellen Punkt und zeichnet sich durch die regelmässige Eiform, zuweilen mit einem stark zugespitzten Pol, aus; ein anderer Theil der Körner besitzt nicht eine so regelmässige Form und entbehrt des hellen Punktes.

Ausser den beschriebenen Formen beobachtet man an denselben Präparaten Leukocyten von ziemlich regelmässiger Form mit scharfen Umrissen und mit einem schwach grünlich gefärbten Kerne. In ihrem Protoplasma befinden sich in grosser Menge grobe Körner verschiedener Grösse, die regelmässig rund sind (s. Taf. VIII, Fig. 6 u. 7); diese Granula sind ebenfalls dunkelviolett tingirt. Es ist zu bemerken, dass die runden Granula niemals einen centralen hellen Punkt besitzen. Diese Art von Leukocyten macht im Vogelblute die Minderzahl aus.

In demselben mit der Mischung aus Eosin und Hämatoxylin nach Ehrlich gefärbten Hühnchenblute begegnet man Leukocyten mit ungewöhnlich origineller Protoplasmafärbung. Auf den ersten Blick scheint ihr Protoplasma von ziemlich dicken Fäden durchzogen; letztere sind gleich den Kernen durch Hämatoxylin dunkelblauviolett tingirt, wobei die Fäden im Allgemeinen schwächer gefärbt erscheinen; ihrer Tinktion ist häufig Eosinfärbung beigemengt. Die allgemeine Anordnung der Fäden erinnert an diejenige der in einem Knäuel zusammenliegenden Chromosomen. An einzelnen Elementen gelingt es zu beobachten, dass sich die helleren Räume zwischen den erwähnten Fäden bald als längere, bald als kürzere, verschieden dicke spindelförmige Figuren präsentiren, die häufig an beiden Enden zugespitzt sind. Auf diese Weise macht es den Eindruck, als ob die stäbchenförmigen Granula in diesen Leukocyten ungefärbt geblieben und die zwischen den Granula durchscheinenden Felder des Protoplasmas durch Hämatoxylin oder durch die Mischung des letzteren mit Eosin tingirt wären (s. Taf. VIII, Fig. 8, 9, 10). Dasselbe Bild erhält man auch an mit neutraler Lösung gefärbten Präparaten, wenngleich in letzterem Falle die Bilder weit weniger deutlich sind.

Durch diesen Umstand lässt sich vielleicht anch die löchrige Beschaffenheit des Protoplasmas der von Us k ow geschilderten eigenthümlichen Leukocytenformen erklären. 
Bei der Färbung mit der sauren Lösung ron Ehrlich lassen sich in einigen Leukocyten die stäbchenförmigen Granula durch Eosin tingiren. Nach $\mathrm{S} \mathrm{eh}$ war $\mathrm{ze}^{\mathrm{1}}$ ) gehören die im Blute and in den blutbildenden Organen der Taube vorkommenden Leukocyten zur Kategorie der eosinophilen Bildungen, da hier nur solche Formen beobachtet wurden, die die Eosinreaction gaben.

Im Blute eines anderen Hühnchens wies die vorwiegende Mehrzahl der Leukocyten bei der Färbung mit der zweiten E h r l i c h'schen neutralen Farblösung (saures Fuchsin + Methylenblau) eine Körnung auf, welche aus einzelnen, zuweilen stark ausgezogenen Bildungen von verschiedener Dicke und mit zugespitzten Enden bestand. Diese Körner färbten sich deutlich violett. An schwächer tingirten Bildungen dieser Art gelingt es, im Centrum vieler Stäbchen einen runden Punkt zu erkennen, der weit intensiver dunkelviolett gefärbt ist und deshalb auf dem allgemeinen helleren Grunde der stäbchenförmigen Bildung scharf hervortritt (s. Taf. VIII, Fig. 4).

Neben den beschriebenen granulirten Leukocyten befinden sich in demselben Blute, wenngleich in weit geringerer Menge, noch Elemente mit Granula von regelmässiger runder Form.

Im Blute eines dritten Hühnchens wurden bei der Tinction mit der neutralen Mischung nach Spilling (saures Fuchsint Methylgrün) Leukocyten mit stäbchenförmigen Körnchen angetroffen, die wie im vorigen Falle auch mit einem centralen runden, intensiv dunkelviolett tingirten Punkte versehen sind (s. Taf. VIII, Fig. 5). Auch im gegebenen Falle wurden nicht in allen Körnern eines und desselben Leukocyten diese centralen Bildungen wahrgenommen; hei der Mehrzahl der Leukocyten zeigten die stäbchenförmigen Granula keine centralen Punkte.

Wie beim Hühnchen, so kommen auch beim Wespenfalken ausser den neutrophilen stäbchenförmigen Körnern noch ox yphile vor.

Hier sei bemerkt, dass die stäbchenförmigen Granula kein ausschliessliches Zubehör der farblosen Elemente im Vogelblut ausmachen, wie das bisher angenommen wurde.

1) Schwarze, Ueber stäbchenhaltige Lymphzellen bei Vögeln. Centralblatt f. d. med. Wissenschaft, 1880. 
So fand ich diese Form in einem Falle auch im Milyvenenblute einer schwangeren Katze. Bei der Färbung mit der neutralen Lösung von Ehrlich oder Spilling treten diese Bildungen sehr deatlich hervor; sie erscheinen bald als ctwas verlängerte ovale Körner, zuweilen mit zugespitzten Enden, bald als kurze, dicke Stäbchen mit stumpfen oder abgerundeten Enden und schliesslich als dünne, lange Stäbchen, deren Längc das Doppelte oder Dreifacbe, und die Dicke die Hälfte der entsprechenden Dimensionen der kurzen Stäbchen beträgt. In der Melızahl der Fälle sind in einer Zelle Granula von ungefähr gleicher Grösse und Form vorhanden, nichtsdestoweniger beobachtet man ziemlich häufig auch solche Elemente, in welchen ausser den kurzen Stäbchen noch lange und schmale in verhältnissmässig. geringer Zahl vorkommen. Einige. Elemente entlalten neben den stäbchenförmigen eine bestimmte Anzahl von runden Körnern. Leukocyten mit stäbchenförmigen Granula waren im betreffenden Blute vorwiegend, während eine erhebliche Minderzahl von farblosen Blutelementen ausschliesslich runde Granula hatte.

In den stäbchenförmigen Körnern des Katzenblutes gelang es mir nicht, centrale helle oder dunkle Punkte nachzuweisen.

Die Existenz von Körnern einer so eigenthümlichen, häufig höchst regelmässigen Form, die in manchen Fällen, wie wir geseben haben, einige Differenzirungsmerkmale in ihrer Substanz und dementsprechend einen complicirteren Bau darbieten, und die dabei ausschliesslich nur in den farblosen Blutelementen vorkommen, lässt mit grosser Wahrscheinlichkeit bebaupten, dass diese Bildungen den Leukocyten eigenthümlich scin müssen, und dass sie nicht ausserhalb dicser letzteren, sondern inuerhalb derselben entstehen, als ein Produkt ihrer Lebensthätigkeit, als der Ausdruck ibrer Lebensfunktion, deren Sinn und Bedeutung bisher ein ungelüstes Räthsel bleibt.

Diese Vermuthung g.cwinnt noch mehr an Wabrscheinlichkeit, wenn man den Umstand in Frwägmng zieht, dass eine solche charakteristische Körnung nicht nur in den Lenkocyten des Vogelblutes, sondern auch bei einigen Säıgethieren (Katze) vorkommt, dass den Granula der farblosen Elemente iiberhaupt ein eigenthümliches Verhalten zu den Farbstoffen eigen ist, wie dies die Untersuchungen $E h_{1} r \mathrm{l}$ c $\mathrm{b}$ 's und seiner Schüler gezeigt haben, und dass endlich die granulirten Leukocyten nicht als ein 
Einige Benerkungen zur Morphotogie und Entwickelung etc. 155

zufälliger Blutbestandtheil, welcher ausschliesslich dieser oder jener Thierart angehört, anzusehen sind, sondern sich beständig im Blute befinden, wobei sie bei Reprïsentanten sowohl der höheren, als auch der niederen Thierspecies beobachtet werden.

So fand $\mathrm{Knoll}^{1}$ ) farblose Blutkörperchen mit oxyphiler Körnung bei einigen Echinodermata (Pedata), Würmern (Polychaetae) und Weichthieren (Cephalopoda), oxyphile and neutrophile Granula beobachtete er in den Leukocyten einiger Species von Weichthieren (Lamellibranchiata) und bei einigen Tunicata (Salpa).

Gleich Löwit spricht auch Knoll sich über das Verhalten zwischen Keru und Granulabildung im Protoplasma der Leukocyten aus. Er macht unter anderem aufmerksam auf das umgekehrte Verhältniss zwischen der Zahl und Grösse der Gramula einerseits und der Grösse des Kernes andererseits. Namentlich bei den Tunicata sah er mit sehr grossen Körnern gefüllte Zellen, während ihre Kerne durch ilure geringe Grösse auffielen und irgend welche Structureigenheiten nicht aufwiesen, "so dass", sagt der Autor, "sich der Gedanke an eine Wechselbeziehung zwischen Körnerbildung und Ernährung des Kernes wohl kaum von der Hand weisen lässt, um so weniger, da sich auch Zellen finden, die mit durch Kernfärbungsmittel tingiblen Körnern erfüllt sind, einen von diesen unterscheidbaren Kern aber nicht erkennen lassen".

Auch Tetten hamer ${ }^{2}$ ) vernuthet anf Grund der Untersuchung von degenerirenden Spermatocytenkernen bei Salamandra maculosa, bei Karyolysis bilde sich auf Kosten des Kernchromatins acidophile Substanz (Färbung mit Eosin), welehe durch Phagocytose vom Lenkocytenkörper aufgenommen wird und hier als $\alpha$-Körnung (Ehrlich) auftritt. Bei der Kerndegeneration scheidet das Chromatingerïst eine Substanz aus, welche sich zum Unterschied vom Chromatin durch die gewöhnlichen Kernfärbungsmittel nicht mehr tingiren lässt, dagegen Eosin und die übrigen sauren Farben (Orange, Indulin, Nigrosin, saures Fuchsin)

1) Knoll, Ueber die Blutkörperchen bei wirbellosen Thieren. Wien 1893.

2) Tettenhamer, Ueber die Entstehung der acidophilen Leukocytengranula aus degenerirender Kernsubstanz. Anatowisch. Anzeiger VIII, 1893. 
gut aufnimmt. Diese acidophile Substanz tritt gleich einer Flüssigkeit in den Zellleib über, bald als grössere, bald als kleinere kugelförmige Tropfen. Dabei kann die Zelle einen Theil ihrer Tropfen verlieren, und in derselben bildet sich wieder acidophile: Substanz auf Kosten des Kernchromatins. Dieser Erneuerungsprocess wïhrt so lange, bis das Chromatin ganz und gar verbraucht wird bei der fortschreitenden Abnahme des Zellleibes, von welchem zuletzt nur eine geringe, fast ungefärbte, formlose Masse übrig bleibt.

Schon a priori muss bei normalem Zustande des Organismus im Blute und in der Lymphe ein Zerfall der Zellelemente in grosser Menge existiren, umsomehr in pathologischen Fällen. Durch diesen letzteren Umstand erklärt $\mathrm{Tetten}$ hamer das Auftreten der eosinophilen Zellen unter pathologischen Bedingungen in bedeutenderem Maasse, als in der Norm.

Die Substanz der acidophilen Granula kann sich, nach Tettenhamer's Ausicht, auch auf Kosten des Keratohyalins bilden, welches nach Mertsehing direkt aus dem Chromatin der zu Grunde gegangenen Kerne von verbornten Zellen entsteht.

Zu Gunsten dessen, dass eine Verwandlung der Kernsubstanz (Chromatin) möglich sei, sprechen folgende Beobachtungen: In den blutbildenden Organen der von mir untersuchten Thiere fand ich besondere Riesenzellen, deren charakteristische Eigenschaft die in ihrem Protoplasma in grösserer oder kleinercr Menge vorhandenen grossen tropfenförmige Bildungen vorstellten. Diese Riesenzellen haben dem Aeusseren nach nichts Gemeinsames mit den im Knochenmarke, theilweise in der Milz gewöhnlich vorkommenden Riesenzellen.

Ich beobachtete dieselben in der Milz erwachsener Hunde, junger Hunde, der Katze, des Meerschweinchens, Kaninchens und der Taube. In der Milz sind sie am meisten vertreten und liegen stets zwischen den Elementen der $\mathrm{Ma}$ a pigh $\mathrm{i}$ 'schen Körperchen, hauptsächlich an der Peripherie der letzteren; cs werden zwar einzelne Exemplare auch in den mehr centralen Theilen der Malpig hi'schen Körperchen beobachtet. Zuweilen liegen Gruppen dieser Riesenzellen längs einem Gefässe. In der Milzpnlpa selbst kommen sie weit seltener vor.

Im Knochenmarke sind sie überhaupt bedeutend weniger 
Einige Bemerkungen zur Morphologie und Entwickelung etc. 157

vorhanden; verhältnissmässig viel babe ich sie bei einem jungen Hunde und bei einer Taube gesehen.

In den Lymphdriisen werden diese Bildungen im Allgemeinen in grösserer Anzahl als im Knochenmark angetroffen: besonders zahlreich waren dieselben in den Lymphdrüsen eines erwachsenen Hundes, eines Meerschweinchens und eines jungen Hundes. Hier sind sie sowohl in den Follikeln der Rindeschicht als auch in den Follikularsträngen vorhanden.

Die in Rede stehenden Riesen\%ellen zeichnen sich nun durch eine grosse Menge von Protoplasma und einen relativ sehr kleinen Kern aus; letzterer lässt sich nur schwach tingiren, da das Chromatin in ihm höchst spär $\overline{l i c h}$ enthalten ist. Der Kern besitzt eine unregelmässige Form, die Struktur desselben ist undeutlich; manchmal, was sehr selten ist, enthält eine Zelle scheinbar zwei Kerne. Die Grenzen des Zellleibes sind nicht scharf ausgeprägt; das Protoplasma färbt sich schwach, viel häufiger erscheint es fast farblos und tritt scharf zwischen den übriger tingirten Elementen durch sein blasses Aussehen hervor.

Im trüben Protoplasma der Riesenzellen ist es zuweilen unmöglich, irgend welche fremdartige Bildungen wahrzunehmen; weit hänfiger jedoch findet man in demselben eine bestimmte Anzahl ron tropfenförmigen Gebilden, die durch Hämatoxylin eine intensive und gleichmässige Färbung erhalten. Diese Tropfen haben häufiger eine regelmässig runde Form, sind aber stets ungleich gross; unter ihnen begegnet man Gebilden sehr geringfügiger Grösse, von kleinsten Pünktchen bis zu sehr grossen Tropfen, die nach ihren Dimensionen den Erythrocyten sehr nahe stehen. Bei dreifacher Färbung cler Präparate (Rubin+ Hämatoxylin+Helianthin) erscheinen die Tropfen durch Rubin gesättigt roth gefärbt.

Seltener besitzen die Tropfen eine ovale Form. Bisweilen beobachtet man Tropfen von mehr unregelmässiger und complicirter Form, wie auf Taf. IX, Fig. 8, 9, $13 \mathrm{c}$ abgebildet ist. Letztere Form $(13 \mathrm{c})$ erinnert an die in den Leukocyten des Vogelblutes beschriebenen stäbchenförmigen Körner mit einem centralen hellen Punkte; ich habe diese Form an sämmtlichen von mir untersuchten Präparaten nur ein einziges Mal beobachten können. Zuweilen gelingt es, im Centrum der runden Tropfen einen hellen Punkt, zn erblicken (s. Taf. IX, Fig. 7); in manchen 
Fällen sind im Tropfen zwei durch Hümatoxylin kaum gefärbtc und deshalh bellere, runde Punkte vorbanden; dieselben liegen an der Peripherie der Tropfen einander gegenüber, sodass der zwischen ibnen gelegene und durch Hümatoxylin intensiv gefärbte Theil des Tropfens an den Buchstaben $x$ erinnert (s. Taf. IX, Fig. 13 b).

Bei Doppelfärbung (Hämatoxylin+Orange) kommen in den genanuten Riesenzellen neben den durch Hämatoxylin tingirten tropfenförmigen Gebilden auch solche zum Vorschein, die mehr oder minder intensiv und dahei gleichmässig gelb (Orange) gefärbt sind. Ausser diesen allenthalben gelben giebt es noch solche, welche theils gelb (Orange), theils schwarz (Hämatoxylin) gefärbt erscheinen. Unter letzteren doppeltgefärbten Tropfen werden Formen beobaclitet,; die der Mondseheibe ähnlich sind; eine Hälfte derselben ist.gelb, die andere sehwarz; in manchen Fällen erscheint der durch Hämatoxylin gefürbte Theil der Scheibe als Mondsichel, die Scheibe selbst ist dabei gelb. Die beschriebenen Formen erinnern sehr an die versehiedenen Phasen einer Mondfinsterniss. Zuweilen ist der centrale Theil der Scheibe gelb tingirt, während an ihrer Peripherie nur ein mebr oder minder schmaler, schwarzer Ring (Hämatoxylin) nachbleibt.

Zwischen beiden verschieden gefärbten Theilen eines und desselben Tropfens existirt keine scharfe Grenze; im Gegentheil, eine Farbe geht allmählich und unbemerkbar in die andere über.

Kurz, es macht den Eindruck, als ob die Substanz der Tropfen allmählich ibre chemische Konstitution ändere, in Folge dessen ein anderes Verhalten derselben zu den Farbstoffen zu Stande kommt: sie verliert allmählich die Fühigkeit, sich mit Hämatoxylin $z u$ färben und beginnt Orange aufzunehmen, bis endlich die durch Hämatoxylin tingible Substanz verschwindet und der ganze Tropfen durch Orange gelb gefärbt erscheint.

Woher stammen nun diese eigenthümlichen, Hämatoxylin gierig aufnehmenden tropfenförmigen Gebilde?

Ihr Ursprung ist mit grosser Wahrscheinlichkeit auf das Kernchromatin zurtickzuftuhren. Wenigstens sprechen dafür folgende von mir beobachtete Bilder:

Innerbalb der beschriebenen Riesenzellen kann man ausser ihren eigenen Kernen und tropfenförnigen Schollen härffig nock besondere Einschlüsse selen, welche ganze im Körper der Riese:ı 
Einige Bemerkungen zur Morphologie und Entwickelung etc. 159

zellen selbst gelegene Zellelemente vorstellen, wobei sicb das Protoplasma der ersteren in der Näbe der eingeschlossenen Elemente so za sag.en verdünnt und $\mathrm{um}$ sie Vacuolen bildet, wie das auf Taf. IX, Fig. 7, 11, 12 abgebildet und besonders deutlich auf Taf. IX, Fig. $10 \mathrm{zu}$ sehen ist.

Die Kerne dieser innerhalb der Riesenzellen geleg'enen Zellen erleiden eine Reihe von successiven Veränderungen. Anfangs thun sich diese Verïnderungen in dem Verwischtsein der Kernstruktur kund (Taf. IX, Fig. 7, 8, 11, 12, 14). Darauf werden die Kerne etwas blass, theils vielleicht in Folge von Verlust der Chromatinsubstanz, theils deshalb, weil das Chromatin zu einer kleinen Menge dicker Strahlen (Fig. 8, 10, 11) oder Schollen zusammenfliesst. Dank dem letzteren Umstande bilden sich im Kerne grössere oder kleinere Bezirke, die durch Hämatoxylin schwach oder gar nicht gefärbt sind.

Die weitere Veränderung besteht in der Bildung von Tropfen aus der zusammenfliessenden Chromatinsubstanz. Die Tropfen liegen bisweilen in dew vollkommen unveränderten protoplasmatischen Körper des von der Riesenzelle aufgenommenen Elementes, welches scharf contourirt und noch die Fähigkeit sich zu färben beibehalten hat (Fig. 10); häufiger jedoch zeigt auch das Protoplasma der eingeschlossenen Elemente schon etliche Veränderungen: der Zellleib nimmt Farben schwach auf, verliert seine scharfen Umrisse und verschwimmt gleichsam mit dem Protoplasma der Riesenzelle, so dass in demselben an Stelle der vorher in ihm gelegenen fremden Zelle nur ein hellerer Fleck mit undeutlichen Umrissen und deutlich zu unterscheidenden Nachbleibseln des zerfallenen Kernes als Tropfen (Fig. 7) verbleibt. Oft ist es sogar unmöglich, den erwähnten hellen Fleck zu sehen, und die Tropfen liegen im Protoplasma der Riesenzelle selbst. Zuweilen verliereu die zerfallenden Kerne den grössten Theil ihres Chromatins, so dass von ihm nur eine ringförmige Figur übrig bleibt, die aus länglichen, gebogenen Chromatinschollen (Fig. 9) besteht. Die Abbildungen 14 und 15 stellen verschiedene Figuren von zerfallenen Kernen vor. Elemente mit solchen Kernen werden dann und wann auch ausserhalb des Riesenzellenleibes, unter den Milzzellen (z. B. bei dem Meerschweinchen) beobachtet.

Folglich sind die beschriebenen Zellen Gigantophagocyten, 
innerhalb deren die von ihnen aufgenommenen Zellelemente einem destructiven Processe anheimfallen, in Folge dessen das Protoplasma der letzteren verschwindet und ihr Kern in Häufchen grösserer oder kleinerer Chromatintröpfchen verwandelt wird. Die Substanz dieser letzteren ändert ibrerseits ihre chemische Beschaffenheit, weswegen im Protoplasma der Gigantophagocyten durch Orange gelb tingible tropfenförmige Bildungen erscheinen. Also bildet sich aus dem Kernchromatin eine netue Substanz, die die Verwandtschaft zum Hämatoxylin allmählich verliert (letzteres tärbt die Zellkörnung gewöhnlich nicht). Anstatt dessen (Hämatoxylin) ninumt dieser neue Körper saures Orange und andere saure Farben (Rubin, Aurantia, Eosin), welche auch die bekannten. Leukocytenkörnchen tingiren, sehr gut auf.

Diese Thatsache bestätigt theilweise die Schlüsse Tettenhamer's über die Entstehung der acidophilen Substanz aus dem Kernchromatin und spricht ebenfalls für die Möglichkeit einer Betheiligung des Kernes an der Bildung von Zellkörnung, wie das $\mathrm{L} o ̈ \mathrm{w}$ it und $\mathrm{Kn}$ oll vermutheten.

Den geschilderten Gigantophagocyten ähnliche Zellen hat R. Heidenhain ${ }^{1}$ ) in den Darmzotten gesehen. Er lässt sie. aus gewöhnlichen Lymphzellen entstehen.

An den Präparaten R. Heidenbain's sind die Kerne der aufgenommenen Leukocyten bald als oblonge, ziemlich schmale, gebogene, homogene Gebilde, bald als $2-3$ homogene Tropfen verschiedener Grösse, endlich als schmale, kommaähnliche Stäbchen gezeichnet. Auf der Abbildung 3 (Taf. IX, Fig. 23) ist (undeutlich) sogar das scheibenförmige bomogene, gelbliche Gebilde mit dem kommaähnlichen, homogenen Ueberbleibsel des Kernes (roth) dargethan. Dieses Gebilde liegt im Phagocytenleibe (der ebenfalls mehr intensiv gelb gefärbt ist), von welchem es durch einen ziemlich breiten, farblosen Ring getrennt ist. Diese Abbildung erinnert an die von mir geschilderten Körperchen (Taf. IX, Fig. 10).

Ausser dem oben Geschilderten finden wir in den Beobach-

1) Heidenhain, R., Beiträge zur Histologie und Physiologie der Dünndarmschleimhaut. Archiv für die gesammte Physiologie, Bd. $43,1888$. 
Einige Bemerkungen zur Morphologie und Entwickelung etc. 161

tungen $\mathrm{K}$ os sel's ${ }^{1}$ ) einige Hinweisungen auf die Aehnlichkeit der Reactionen in Betreff der Farbstoffe zwischen der Substanz der Leukocytengranula einerseits und zwischen den den Kern bildenden Substanzen andererseits. Verschiedene Substanzen, die die Zelle aufbauen, mit der neutralen Lösung Ehrli ch's (saur. Fuchsin+Methylgrün) färbend, ward Kossel das ungleiche Verhalten derselben zu den genannten Farben gewahr: während das Eiweiss roth und die freie Nucleinsäure grün gefärbt wird, nehmen die Substanzen, welche durch Verbindung beider Körper zu Stande kommen (Nucleinkörper), bei derselben Behandlung eine gemischte Färbung an.

Posner ${ }^{2}$ ) erhielt analoge Daten.

Diese Ergebnisse liefern uns zugleich einen Anhaltspunkt für die Entscheidung der Frage nach der chemischen Natur der Leukocytenkörner.

Was die Gigantophagocyten betrifft, so ist noch folgendes zu bemerken. In denselben wurden häufig Gebilde beobachtet, welche den von $\mathrm{W}$ is s o z k y beschriebenen Bildern seiner Hämatoblasten sehr ähnlich waren. Auf Taf. IX, Fig. 10 sieht man innerhalb einer Riesenzelle ein scheibenförmiges Gebilde von sehr regelmässiger, runder Form und mit scharf ausgeprägten Contonren. In demselben sind zwei runde tropfenförmige, homogene, durch Hämatoxylin gefärbte Schollen eingeschlossen. Die Substanz dieses scheibenförmigen Körperchens ist viel intensiver tingirt (Orange, Aurantia), als das Protoplasma der Riesenzelle; sie ist dabei homogen und ist von dem schwach gefärbten, trüben Protoplasma durch einen schmalen ringförmigen, vollkommen farblosen Streifen getrennt. So scheint es, als ob diese Körperchen mit dem Locheisen im Protoplasma der Riesenzelle ausgehauen wären, was auch der Beschreibung: Wissozk $y^{\prime}{ }^{3}$ ) vollkommen entspricht.

1) Kossel, Ueber Lymphzellen. Gesellschaft der Charité-Aerzte. Verein für innere Medicin 5. Febr. 1894. Berliner klin. Wochenschr. Vr. 38, 1894.

2) Posner, Farbenanalytische Untersuchungen. Verhandl. des zII. Congresses f. innere Medicin. Wiesbaden 1893.

3) Wissozky, Jeber das Eosin als Reagens auf Hämoglobin and die Bildung von Blutgefässen und Blutkörperehen bei Säugethierand Hühnerembryonen. Arch. f. mikr. Anat., Bd. XIII, 1877. 
Ausser den beschriebenen Gebilden kommen oft in den Riesenzellen ganz ähnliche scheibenförmige scharf contourirte und vollkommen isolirte Körperchen vor, welche sich von den vorhergehenden nur durch die Abwesenheit von schwarzen Tropfen oder Kernresten unterscheiden.

Weiterbin kann man häufig innerhalb der Riesenzellen ganze Zellen mit noch conservirten Kernen wahrnehmen. Auf Taf. IX, Fig. 7 ist im Protoplasma des Phagocyten ein Körperchen dargestellt, dessen Kern gut gefärbt ist und eine radiäre Anordnung. der Chromatinschollen zeigt; das Protoplasma des Körperchens ist homogen, gelb gefärbt (Aurantia), dabei intensiver als das Protoplasma des Phagocyten. Der in das Innere des Phagocyten gewendete Theil des Zellenleibes ist scharf contourirt und deutlich mit einem farblosen Streifen. umringt. Auf Taf. IX, Fig. 12 ist ein solches Körperchen abgebildet; dasselbe ist durch Rubin roth gefärbt; die Grenzen des Protoplasmas sind deutlich ausgeprägt; die Kernstructur ist etwas verwischt. Das Körperchen selbst liegt scheinbar in einer grossen Vacuole.

In dern Protoplasma der Gigantophagocyten kommen auch häufig isolirte Körner vor, zuweilen in ziemlich grosser Zahl. Die Körner sind entweder so klein, wie ein Pünktchen, oder grösser, und lassen sich durch Aurantia, Orange und Eosin gut tingiren. Diese Bilder entsprechen theilweise der Beschreibung von $\mathrm{Nic}$ olaides ${ }^{1}$ ).

Die soeben betrachteten Bilder können nicht, wie schon oben erwähnt wurde, im Sinne einer Neubildung ausgelegt werden; sie sind eher als ein Product regressiver Verändelungen aufzufassen, da die von den Phagocyten aufgenommenen Elemente an sich die Spuren eines allmählichen destructiven Processes tragen, welcher mit einer vollständigen Zerstörung der aufgenommenen Zelle endigt. Diese Vermuthung gewinnt um so mehr an Wahrscheinlichkeit, als die Gigantophagocyten rielfach namentlich an solchen Stellen vertreten sind, wo Spuren einer Neubildung von rothen Blutkörperchen nicht gefunden werden, z. B. in den M a l pig hi'schen Körperchen der Milz.

1) Nicolaides, Ueber intracellulare Genese von rothen Blutkörperchen im Mesenterium des Meerschweinchens. Arch. f. Anat. $u$. Physiol., 1891, Heft 5 u. 6. 
Wir kennen aber sehr wohl zahlreiche Beobachtungen von dem Untergange rother Blutkörperchen, die von Phagocyten aufgenommen worden waren; ich will hier nur auf die Arbeiten von $\mathrm{Riess}^{1}$ ), Litten ${ }^{2}$ ), Grohé $\left.{ }^{3}\right), \quad$ osler ${ }^{4}$ ), Gibson ${ }^{5}$ ), Geelmuyden ${ }^{6}$ ), $\mathrm{H}_{0 \mathrm{yer}} \mathrm{r}^{7}$ ) und $\mathrm{Kusnet} \mathrm{z}$ of $\mathrm{f}^{8}$ ) verweisen.

Alles dieses muss unbedingt in Erwägung gezogen werden bei der Beurtheilung der Frage über die etwaige intracelluläre Entwickelung rother Blutkörperchen, da wir einerseits keine unwiderlegbaren Thatsachen besitzen zur Entscheidung der Frage, ob im gegebenen Falle eine junge neuge bild ete Zelle vorliege; andererseits viele Beobachtungen uns die Aufnahme von Zellen in andere (in Phagocyten) beweisen.

\section{Die Entwickelung der Blutelemente.}

Die blutbildenden Organe lassen, so weit wir es jetzt wissen, zweierlei Arten von Elementen unterscheiden, welche ihren morphologischen Eigenschaften nach von einander scharf getrennt sind. Das sind die Leukoblasten und die ron denselben abstammenden farblosen Blutkörperchen (Leukocyten) einerseits and die Erythroblasten und die von ibnen entstehenden kernhaltigen Erythrocyten, welche sich später in die endgültige Form, d. h. in gewöhnliche kernlose Erythrocyten verwandeln, andererseits.

1) Riess, Beitrag zur pathologischen Anatomie des Knochenmarkes bei perniciöser Anämie. Centralbl. f. cl. med. Wissensch., $1881 \mathrm{Nr} .48$.

2) Litten, Ueber das Vorkommen blutkörperhaltiger Zellen im Knochenmark. Ibid. Nr. 50.

3) Grohé, Ueber das Verhalten des Knochenmarks in verschiedenen Krankheitszuständen. Berl. klin. Wochenschr., 1881, Nr. 44.

4) Osler, Note on cells containing red blood-corpuscles. Jahresber. üb. d. F. d. Anat. u. Phys. Hofmann-Schwalbe, Bd. XI, 1883.

5) Gibson, The blood-forming organs and blood-formation. Journ. of Anat. and Physiol. norm. and pathological, 1885, Vol. XX, P. II-III.

6) Geelmuyden, Das Verhalten des Knochenmarkes in Krankheiten und die physiologische Function desselben. Virchow's Arch., Bd. 105, 1886.

7) Hoyer, Beitrag zur Kenntniss der Lymphdrüsen. Jahresber. üb. d. F. d. Anat. u. Phys., Bd. XVIII, 1890.

8) Kusnetz off, Ueber die Blutkörperchen enthaltenden Zellen der Milz. Ibid. Bd. II, 1875. 
Erythroblasten. Diese Gebilde wurden im Knochenmark und in der Milz sowohl bei jungen, als auch bei erwachsenen Thieren beobachtet. Bei letzteren ist in der Milz die Zahl dieser Elemente stets viel geringer, als im Knochenmarke. Die jüngsten Formen dieser Zellen zeichnen sich durch ihre bedentende Grösse aus, die die Dimensionen eines gewöhnlichen rothen Blutkörperchens mehrfach übertrifft. Sie sind meistentheils vollkommen rund; nur selten trifft man Elemente von mehr oder weniger länglicher oder ovaler Form. Dabei erscheinen ihre Contouren als feine Linien, welche sich von dem ïbrigen helleren Theile des Zellprotoplasmas scharf abheben. Der Zellleib umgiebt den Kern in der Gestalt eines hellen, aus vollkommen homogener Substanz bestehenden Ringes.

Der Kern macht den umfangreichsten Theil der Zelle aus. Die Kernform ist gleich dem Zellleibe bald vollkommen rund, bald mehr oder weniger oval. Der Kern behält jedoch stets dic Form einer regelmässigen Figur und zeigt im Ruhezustande an seiner Peripherie keine Vertiefungen, Vorsprünge, Krümmungen, Einschnürungen etc. Die Erythroblastenkerne werden stets, dank dem hier reichhaltig vertretenen Chromatin, durch Hämatoxylin sehr intensiv gefärbt, so dass sie schon der Färbungsintensität nach von den Kernen der übrigen Zellelemente unterschieden werden. Die Kerne besitzen stets scharfe Umrisse. Die Peripherie des Kernes ist ron einer mehr oder weniger deutlich ausgeprägten, dunklen (durch Hämatoxylin) Linie begrenzt, von welcher unmittelbar zum Centrum des Kernes hin ziemlich massive Chromatinschollen, die ebenfalls durch Hämatoxylin intensiv tingirt werden, binziehen. Diese Schollen haben meistentheils eine längliche Form und ordnen sich in der Richtung der Kernradien, an Radspeichen erinnernd. Die Chromatinschollen sind jedoch nicht immer gleich lang: einige sind riemlich kurz, so dass sie in der Mitte zwischen der Peripherie und dem Kerncentrum unterbrochen werden; andere wieder, und dabei die Minderzahl, ziehen bis an den centralen Theil des Kernes, wobei sie meistentheils hier mit einer im Centrum gelegenen Chromatinscholle zusammenfliessen. Seltener werden statt einer centralen Scholle zwei, noch seltener drei beobachtet. Der Dicke nach unterscheiden sich die einzelnen Chromatinstrahlen nur wenig, während die Dicke eines und desselben Strahles auf der ganzen 
Einige Bemerkungen zur Morphologie und Entwickelung etc. 165

Strecke eine ungleiche ist. Der periphere Theil der Chromatinstrahlen oder der radiär angeordneten Chromatinschollen erscheint gewöhnlich etwas verdickt im Vergleiche zu dem schmalen, zum Centrum des Kernes zugewandten Ende derselben. Eine mehr regelmässige radiäre Anordnung der Chromatinstrahlen wird an den kleineren Kernen, welche zu den späteren Entwickelungsformen der Erythroblasten gehören, beobachtet, während an den grösseren Kernen (den jüngsten Formen) die Strahlenanordnung nicht immer eine so regelmässige ist; einige Strahlen ziehen mehr oder weniger schräg zu einem ausserhalb des Kerncentrums gelegenen Punkte. Je grösser im Allgemeinen der Kern ist, desto kürzer und massiver sind die einzelnen Chromatinstrahlen, welche sich oft als kurze, an der Kernperipherie angeordnete Zacken präsentiren. Von der Kerngrösse ist auch die Zahl der Strahlen direct abhängijg. Bei dreifacher Fürbung werden einige Schollen durch Rubin roth gefärbt, während andere durch Hämatoxylin schwarze Tinction erhalten.

Die weitere Entwickelung dieser primitiven Bildungszellen besteht in der allmählichen und gleichmässigen Verkleinerung der Dimensionen des Kernes, so dass seine regelmässige Form unverändert bleibt. Der progressiven Verkleinerung des Kernes gemäss bildet sein Zèlleib eine immer breiter werdende Zone. Die protoplasmatische Zone ist übrigens an der ganzen Peripherie nicht immer gleich breit, da der Kern zuweilen nicht in's Zellencentrum selbst zu liegen kommt. Im Laufe der Zeit wird auch die Zelle selbst kleiner, aber nicht in dem Maasse, wie der Kern, so dass letzterer stets von einem verhältnissmässig breiteren protoplasmatischen Saume als in den frühesten Entwickelungsstadien umgeben ist.

Parallel mit der Verkleinerung des Kernes vergrössert sich die Färbekraft desselben. Diese Erscheinung wird durch den Umstand erklärt, dass die Verkleinerung der Kerndimensionen etwa cine Eindickung, Condensation, des Chromatins bewirkt. Dieses letztere bildet jetzt eine geringere Menge von Strahlen, welche sich dichter auordnen, so dass die Quantität der übrigen durch Hämatoxylin kaum gefürbten Kernsubstanz ( Kernsaft" ${ }^{*}$ ) allmählich immer kleiner wird. Mitunter werden die Strahlen nach und nach länger; in reiferen Elementen reicht die Mehrzahl der Strablen bis an den centralen Theil des Kernes; letzterer Um- 
stand bedingt eine noch bedentendere Verkleinerung des ron der schwach gefärbten Kernsubstanz eingenommenen Raumes. Einzelne Strahlen werden hierbei zuweilen massiver, dicker.

Mit der Verkleinerung des Kernes wird auch die Anordnung der radiären Strahlen eine regelmässige, sodass man manchmal an kleinen Kernen eine zierliche Kreuzfigur erblicken kann, welche aus vier radiär angeordneten Chromatinstrahlen zusammengestellt ist; die Kernumrisse erhalten dabei eine runde Form.

Mit dem weiteren Verlaufe der Entwickelnng wird der Kern noch kleiner, die einzelnen Strahlen verschmelzen, so dass an den kleinsten Kernen, die zu den endgültigen Phasen der Entwickelung von Erythroblasten gehören, die radiäre Anordnung. des Chromatins oft nur sehr undeutlich ausgesprochen ist; zuletzt erhält der Kern ein vollkommen homogenes Aussehen. In diesem Falle erscheint er als kleiner, homogener, durch Hämatoxylin gefärbter Kreis; seine Form ist regelmässig rund, die Contouren sind sehr scharf ausgeprägt.

Die bis zu minimalen Dimensionen verkleinerten und anf die erwähnte Weise veränderten Kerne werden scheinbar zu weiterer Proliferation unfähig. Hierbei erweist sich der atrophirte, seiner morphologischen Eigenschaften und der functionellen Fähigkeit verlustig gewordene Kern als überflüssiger Bestandtheil und unterliegt deshalb einem endgültigen Zerfalle, auf welchen ein gänzliches Verschwinden desselben folgt.

Der Kern zerfällt zunächst in $2-3$ oder mehrere Fragmente von verschiedener Grösse; dieselben erscheinen als kleine, structurlose-tropfenförmige Gebilde, welche sich stets rom hellen Grunde des homogenen Zellleibes scharf abheben, dank ihrer Fähigkeit, sich durch Hämatoxylin gleichmässig, fast schwarz, zu färben.

Das weitere Schicksal dieser tropfenförmigen Chromatinfragmente ist scheinbar das, dass sie im Protoplasma des Blutkörperchens allmählich aufgelöst werden. Für eine solche Vermuthung spricht der Umstand, dass zuweilen Elemente vorkommen, welche alle charakteristischen Eigenschaften vollkommen ausgebildeter Erythrocyten besitzen, sich aber von diesen letzteren durch die Anwesenheit besonderer Einschlüsse in ihrem Protoplasma unterscheiden. Die genannten Einschlüsse haben meist eine unregelmässige Form; ibre Umrisse sind undeutlich, ver- 
schwommen; ihre Grösse und Menge sind verschieden; sie sind gewöhnlich unregelmässig angeordnet: einige von ihnen liegen in den centralen Theilen des Körperchens, während andere sich in den peripheren befinden; durch Hämatoxylin werden sie sehr schwach aschgiau gefürbt, so dass sie kaum bemerkbar und oft nur mit Mühe aufzufinden sind; zuweilen aber nehmen diese Gebilde dieselbe Farbe auf, wie auch das Protoplasma der Erythrocyten, nur mit dem Unterschiede, dass die Einschlïsse stets etwas intensiver gefürbbt sind. Neben den blassen, graulichen Einschlïssen in den einzelnen Zellen beobachtet man punktförmige, durch Hämatoxylin dunkler tingirte Gebilde.

Diese noch nicht vollkommen ausgebildeten Erythrocyten mit Einschlïssen unterscheiden sich von den gewöhnlichen rothen Blutkörperchen ausser dem Gesagten noch durch verhältnissmässig. bedeutendere Grösse und dadurch, dass sie an ihrer Peripherie keine doppelten Contouren besitzen (s. Taf. IX, Fig. 1f).

Uebrigens zeigt der Kern nur selten keine Erscheinungen von Chromatolyse; derselbe atrophirt dann scheinbar allmählich und wird in Folge von Verlust der Chromatinsubstanz immer blasser, dabei die runde Form beibehaltend. So werden zuweilen einzelne Elemente beobachtet, deren runder Kern stark verkleinert und durch Hämatoxylin sehr schwach, aber gleichmässig auf der ganzen Strecke gefärbt ist.

So erscheinen die rothen Blutkörperchen der Säugethiere als das Resultat einer sehr complicirten Umwandlung der Bildungszellen, der Erythroblasten. Die erwähnte Verkleinerung des Zellvolumens ist das Resultat der Kernverkleinerung, mit anderen Worten, es verfolgt die Zusammenziehung des Zellleibes den Zweck, denjenigen Defect auszufüllen, welcher in Folge von der Verkleinerung und dem Schwunde des Kernes zu Stande kommen müsste. Nur dann, wenn die letzten Spuren von Kernfragmenten vollkommen verschwunden sind, hat die Zelle die Dimensionen und Eigenschatten eines gewöhnlichen rothen Blutkörperchens gewonnen. Taf. IX, Fig. 1 giebt die verschiedenen Entwickelungsphasen der Erythroblasten wieder.

Obrastzow ${ }^{1}$ ) hat ebenfalls körnige rothe Blutkörperchen

1) Obrastzow, Zur Morphologie der Blatbildung im Knochenmarke der Säugethiere. Diss. St. Petersb. 1880 (russisch). 
beobachtet und hält dieselben für unreife Formen. Diese Erscheinung erklärt er jedoch auf andere Weise.

Nach seiner Vorstellung ist in den „blassen Zellen" des Knochenmarkes und in den von ihnen abstammenden „Hämatoblasten" (kernhaltigen rothen Blutkörperchen) während des Lebens diese Kernsubstanz in der ganzen Zelle verbreitet. Bei der postmortalen Starre des Protoplasmas der genannten Zellen verdichtet sich die Kernsubstanz und bildet anfänglich eine Reihe einzelner, feiner Verschmelzungscentren in der Gestalt von Körnern. Diese letzteren ziehen sich späterhin zum Centrum zusammen und erscheinen hier als Kerne. In einigen Fällen füllen diese Körnchen dem Anschein nach das ganze Körperchen aus, während wir in anderen nur 2-3 Körnchen antreffen. In dieser Mannigfaltigkeit der Körnchenzahl oder der Centren der postmortalen Verschmelzung der sich verdichtenden Kernsubstanz erblickt der Autor eize allmähliche Verminderung von Kernsubstanz in den unreifen Blutkörperchen bis zu einem vollständigen Schwunde derselben.

A rndt (citirt bei Obrastzow) nimmt an, dass die elliptischen rothen Blutkörperchen vom Frosch, Triton, sowie von Fischen und Vögeln während des Lebens keine Kerne besitzen. Das Auftreten von Kernen in denselben weise auf eine schwere Störung der Ernährung, auf das Absterben der Zelle hin. Die Blutelemente würden bei der Kernbildung zuerst körnig; später bilde sich dadurch, dass sich die Körner einander nähern, der Kern, welcher jedoch keine netzartige Structur habe, da er nur aus einzelnen Körnern zusammengeballt sei; das Kernnetz sei eine optische Tänschung.

Eine diffuse Anordnung der Kernsubstanz im Zellleibe lässt auch Malassez) zu: seine "Protohämatoblasten" besitzen einen solchen undifferenzirten Kern.

An den von mir untersuchten Objecten habe ich niemals Erythrocyten mit einer grossen Menge von feinen Körnchen in ihrem Protoplasm angetroffen. Das meiste, was die Erythrocyten enthielten, waren $4-5$ verhältnissmässig grobe Körnchen, unter welchen zaweilen auch ziemlich grosse vorhanden waren. Dabei kamen diese Formen ausschliesslich in den blutbildenden Organen vor, niemals wurden sie im Blute gefunden.

Ueber einen Zerfall der Blutkörperchen-Kerne und das Verschwinden der Fragmente durch eine Art Auflösungsprocess berichten indessen eine ganze Reihe von Autoren. Ich nenne

1) Malassez, Sur l'origine et la formation des globules rouges dans la moelle des os. Arch. de physiologie norm. et pathol. 2 Série. T. IX. 1882 N. 1. 
Einige Bemerkungen zur Morphologie und Entwickelung etc. 169

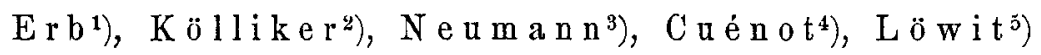
und Askanaz ${ }^{6}$ ).

Nach einer anderen Ansicht ( $R$ in $d \mathrm{fle}$ is c h, $\mathrm{H}$ ow ell, Disse, v. d. Stricht, Ehrlich a. A.) verlieren die kernhaltigen rothen Blutkörperchen ihren Kern durch Ausstossung. E h r li $\mathrm{C}^{7}$ ) nimmt an, dass die Normoblasten (kernhaltige rothe Blutkörperchen, welche der Grösse nach den gewöhnlichen rothen Blutkörperchen entsprechen) ihren Kern ausstossen, während der Kern der Megaloblasten (kernhaltige Elemente, aus welchen sich bci Anämie Riesenblutkörperchen bilden) degenerire.

$\mathrm{M}$ ondino, Osler, Spuler, Eliasberg u. A. stellen dagegen die Entstehung von kernlosen Erythrocyten durch Kernausstossung in Abrede. An meinen Präparaten habeich ebenfalls nichtsdergleichen wahrge$\mathrm{n}$ o m m e $\mathrm{n}$.

El i a s be $\mathrm{g}^{3}$ ) schliesst aus seinen Präparaten, dass der Kernschwund (durch Aufösung in der Richtung von der Peripherie zum Centrum hin) erfolge, indem man die peripheren Theile des Kernes blasser finde, während das Centrum noch dunkler sei.

Es ist jedoch zu bemerken, dass ich niemals Kerne von solchem Charakter gefunden habe, wie sie Eliasberg beschreibt, d. h. Kerne mit einer blasseren, in Resorption begriffenen

1) $\mathrm{E} r \mathrm{~b}$, Zur Entwickelungsgeschichte der rothen Blutkörperchen. Virch ow's Arch. Bd. 34, 1865 .

2) Kölliker, Ueber die Blutkörperchen eines menschlichen Embryo und die Entwicklung der rothen Blutkörperchen bei Säugethieren. Zeitschr. f. rationelle Medicin, Bd. IV, 1846.

3) Neumann, Ueber die Bedeutung des Knochenmarkes für die Blutbildung. Arch. d. Heilkunde, Jahrg. X, 1869.

4) Cúnot, Sur le développement des globules rouges du sang. Comptes rendus, T. 106, 1880.

5) Löwit, Die Umwandlung der Erythroblasten in rothe Blutkörperchen. Sitzungsberichte d. Wien. Akad., Bd. 95, Abth. III, 1887.

6) Askanazy, Blutbefund bei perniciöser Anämie. Deutsch. med. Woch., 1893, Nr. 35.

7) Ehrlich, Anämische Befunde. De- und Regeneration rother Blutscheiben. Farbenanalyt. Unters. z. Histol. u. Klinik des Blutes. Berlin 1891.

8) Eliasberg, Experimentelle Untersuchungen über die Blutbildung in der Milz der Säugethiere. Inaug.-Diss. Dorpat 1893. 
peripheren Schichte; im Gegentheil zeichnen sich in allen Fällen die Erythroblastenkerne, von den frühesten bis zu den spätesten Entwickelungsstadien derselben, durch sehr scharfe Contouren aus (Hämatoxylinfärbung); sogar die Kernfragmente besitzen wenigstens zu Anfang stets ebensolche scharfe Umrisse.

P a p p e n h i m ${ }^{1}$ ) betrachtet den Kernschwund der Erythroblasten als eine einfache Degeneration des Zellkernes, welche auf keinen Fall mit der Degeneration des Zellleibes in Zusammenhang stehe, obgleich die entkernten Zellen als Scheiben nur eine kurze Zeit (vier Wochen) fortleben. Die Metaphase zu den Erythrocythen in Folge von Kernschwund wird in Erytbroblasten von verschiedener Grösse beobachtet und kann in jedem Alter der Zelle anfangen, sowohl in jungen als auch in alten Erytbroblasten. Deshalb kann die Metaphase als Ausdruck für die Reife der Blutzellen nicht dienen. Die Ursache der Metaphase muss in einer Ernährungsstörung der Kernes gesucht werden.

Es ist zu bemerken, dass die von $P$ a p pen heim beschriebene "Radform" der Erythroblastenkerne der Kernstructur der Erythroblasten bei allen von mir untersuchten Thieren sehr ähnlich ist. P a p p e $\mathrm{n}$ e i m hält solche Veränderungen des Kernes für degenerative Erscheinungen. Es ist jedoch schwer, mit $P$ ap pe $n$ hei m's Ansicht übereinzustimmen, wenn , man folgende Umstände in Erwägung zieht. Erstens, ist die Radform ausschliesslich den Erythroblasten eigen; zweitens, wird sie an solchen Elementen beobachtet, welche ibrem Aeusseren nach vollkommen intakt erscheinen, welche die normalen Form- und Structurverhältnisse des Kernes und des Zellleibes beibehalten haben, und ebenfalls keine sichtbaren Abweichungen von der Norm im Sinne der Färbung beider Bestandtheile aufweisen; drittens, kommen Kerne mit solcher Structur bei einer grossen Zabl der Erythroblasten und dabei bei allen untersuchten Thieren vor; an manchen Objecten war diese Form sogar ausschliesslich vertreten. Wenn auch in einzelnen Fällen in den Erythroblasten Kerne mit netzförmiger Anordnung der Chromatinfaiden beobachtet werden, so machen diese Formen stets eine unbedentende MinderzahI aus; eine solche Anordnung des Chromatins kommt übrigens in

1) Pappenheim, Die Bildung der rothen Blutscheiben. Inaug.Diss. Berlin 1895. 
Einige Bemerkungen zur Morphologie und Entwickelung etc. 171

späteren Entwickelungsstadien vor. Wenn dabei an den radförmigen Kernen Erscheinungen des Zerfalles (Karyorrhexis + Karyolysis im Sinne $\mathrm{P}$ a p pen heim's) wahrgenommen werden, so geschieht dies unter besonderen Umständen, beim Absterben der ganzen Zelle innerhalb der Gigantophagocyten (Tafel IX, Fig. $8,10,11,12)$.

Die Vermehrung der Erythroblasten geschieht nach dem Typus der $\mathrm{m}$ i t o t i s c h e n T h e il u $\mathrm{n} g$ ('Taf. VIII, Fig. 16). Die Vermehrungsfähigkeit behalten die Erythroblasten scheinbar so lange, als ihr Kern noch keine bedeutenden Structurveränderungen erlitten hat. Die mitotische Theilung der Erythroblasten wird von den meisten Autoren, welche diesen Prozess beobachtet haben, anerkannt. Askanazy ist es sogar gelungen, unter dem Mikroskope die indirecte Kerntheilung innerhalb eines grossen rothen Blutkörperchens im Blute bei perniciöser Anämie zu beobachten.

Die Frage, ob die Erythroblasten schon von Anfang an hämoglobinhaltige Zellen seien oder ob die ursprünglichen Formen farblos wären, ist verschieden beantwortet worden. Als Vertreter der ersteren Ansicht erscheint B i z z o z e r $0^{1}$ ), nach dessen Meinung bei Vögeln die allerjüngsten Zellen (die sphärische Zelle mit spharischem Kerne) schon durch Hämoglobin gefärbt sei, wenngleich weniger intensiv, als die vollkommen entwickelten rothen Blutkörperchen. Andere Autoren sind der zweiten Möglichkeit geneigt: How ell, Lö wi t, Denys, Fo ̀, Wertheim. M ï ller, Disse u. A. Uebrigens enthalten nach $D$ i s s $e^{2}$ ) die Erythroblasten häufig. Hämoglobin, können aber auch farblos sein. Nach Freiberg's Ansicht ist es schwer, mit Bestimintheit festzustellen, ob die jüngsten Formen Hämoglobin enthalten oder nicht.

Nach v. d. Stricht ${ }^{3}$ ) bilden sich die ersten Erythroblasten während der Localisation des Blutbildungsprocesses in der embryonalen Leber aus den kernhaltigen rothen Blutkörper-

1) Bizzozero, Neue Untersuchungen über den Bau des Knochenmarks bei den Vögeln. Arch. f. mikr. Anat., Bd. š5, 1890.

2) Disse, Blut und Gefässe. Ergebnisse der Anat. u. Entwickelungsgesch., Bd. I, 1891-1892.

3) v. d. Stricht, Le développement du sang dans le foie embryonnaire. Arch. de biologie, T. XI, Fasc. 1, 1891. 
chen des circulirenden Blutes, welche mehr oder weniger dureh Hämoglobin gefärbt sind; später erscheint das Product ihrer Vermehrung in der. Gestalt von farblosen Erythroblasten. Trotz der Meinung $\mathrm{C} u$ én ot's über die Betheiligung des Kernes (die von ibm sich loslösenden Körnchen spielen entweder die Rolle eines Ferments oder erscheinen als Eisenträger) an der Formirung von Hämoglobin leugnet v. d. Stricht jeglichen Zusammenbang zwischen Kernschwund und Hämoglobinbildung, da er in den abführenden Leberkapillaren eine grosse Zahl von schwach tingirten kernlosen rothen Blutkörperchen fand; andererseits wird neben den gefärbten Erythroblasten eine Menge fast ungefärbter kernloser Körperchen beobachtet.

Meine Beobachtungen führen $\mathrm{zu}$ anderen Resultaten: Behufs Beurtheilung der obigen Frage ist am meisten die combinirte Färbung mit Hämatoxylin-Rubin-Helianthin geeignet. An solchen Präparaten sind die hämoglobinhaltigen Erythrocyten bei einem bestimmten Grade der Einwirkung von Helianthinlösung intensiv roth gefärbt, besonders aber diejenigen, welche an der Peripherie des betreffenden Organes liegen, während die in den mehr centralen Theilen gelegenen entweder bedeutend schwächer gefärbt werden, oder gar nicht Rubin aufnebmen, sondern nur durch Helianthin gefärbt werden, welches auch das Leukocytenprotoplasma tingirt. Es zeigt sich nun der Erythroblastenleib in der Mehrzahl. der Fälle gelb gefärbt (Helianthin); indessen kommen an Präparaten aus $M$ üller'schen Flüssigkeit zuweilen einzelne Erythroblasten mit schwach rosa gefärbtem (Rubrin) Protoplasma vor.

Es sind noch besondere Varietäten der Kernform der Erythroblasten zu beachten. In den blutbildenden Organen einiger Thiere werden Kerne angetroffen, welche stark ausgezogen und sehr verjüngt sind, besonders im mittleren Theile, an den Enden aber keulenförmig verdickt, so dass sie eine Hantelform besitzen. Einige Kerne sind erst im Begriffe eine verlängerte Form anzunehmen, sich auszuziehen, während andere schon mehr oder weniger ausgezogen, verjüngt, zuweilen gebogen erscheinen (s. Taf. IX, Fig. 5). Dafür, dass dies Erythroblastenkerne sind, spricht erstens ihre intensive Färbung, welche sie von den schwach tingirten Leukocytenkernen scharf unterscheidet, und zweitens der Umstand, dass an ihren keulenförmig verdickten Enden die 
namentlich den Erythroblasten eigene radiäre Anordnung der Chromatinstrahlen oft deutlich hervortritt. Häufig sind diese hantelförmigen Kerne dem Anscheine nach über dünne Bindegewebebalken oder über eine dünne Gefässwandung geworfen, wobei eine der Verdickungen im Gefässlumen liegt; der mittlere, stark verjüngte Theil des Kernes liegt an der Wandung selbst (dieselbe scheinbar durchbohrend), und der andere verdickte Theil des Kernes ist ausserhalb der Gefässwandung zwischen den Elementen der Milzpulpa angeordnet. Auf Taf. IX, Fig. 6 sehen wir, wie ein Erythroblast durch die Gefässwandung geht. Diirften nicht die soeben angeführten Ergebnisse die Ansicht von $\mathrm{D}$ e $\mathrm{y} \mathrm{s}^{\mathbf{1}}$ ) über eine amöboide Bewegung der Erythroblasten bestätigen? v. d. Stricht, L ö w it ${ }^{2}$ ) und E I i a s b e $r^{\circ}$ streiten übrigens das Vorhandensein einer solchen kategorisch ab. Eli a s b e rg meint, dass der Durchgang der kernhaltigen rothen Blutkörperchen durch die endotheliale Venenwandung der Milzpulpa einfach durch den Druck der sich vermehrenden benachbarten Elemente bedingt werde.

L e u k oblasten. Es sind dies, wie gesagt, die jüngsten Zellformen bei der Entwickelung von Elementen der leukocytären Art. In manchen Organen, z. B. Milz and Lymphdrüsen, localisirt sich der Entwickelungsprocess der genannten Bildungszellen an bestimmten Theilen dieser Organe, von wo aus auch die Neubildung der Leukocyten ausgeht. Solehe locale Herde bilden in der Milz die M a l p i $g$ h i'schen Körperchen, und in den Lymphdrüsen hanptsächlich die Follikel der Rindensubstanz. Im Knochenmark giebt es keine solche isolirte Prodnctionscentren oder Anhäufungen von Körperchen als Lymphfollikel, wie sie $\mathrm{S}$ a n feli $\mathrm{c}^{3}$ ) nennt; hier sind die jungen Zellen ohne Ordnung mit Elementen verschiedener Altersstufen vermischt.

Sowohl die Leukoblasten als auch Leukocyten unterscheiden sich nach ihren morphologischen Merkmalen von den Erythroblasten sehr scharf. Ihr Kern ist stets weit weniger intensiv

1) Denys, Sur la structure de la moelle des os et la genèse dus sang chez les oiseaux. La Cellule. T. W. 1888.

2) Löwit, Die Anordnung und Neubildung von Leukoblasten und Erythroblasten in blutzellenbildenden Organen. Arch. f. mikrosk. Anat., Bd. 38, 1891.

3) Sanfelice, Genèse des corpuscles rouges dans la moellle des os des vertébrés. Arch. italien. de Biologie, T. XIII, Fasc. 1, 1890. 
gefärbt, was durch den verhältnissmässig geringeren Gehalt an Chromatinsubstanz in demselben bedingt wird. Die Kernform ist sogar in den frïhesten Entwickelungsstadien niemals so regelmässig;, wie bei den Erythroblasten, abgeselsen von den weiteren Entwickelung:sformen der Leukocyten, deren Kerne höchst mannigfaltige und unregelmässige Figuren bilden. Schon sehr früh erhalten die Leukoblastenkerne unregelmässige Conturen mit leichten Vertiefungen, Ecken u. s. w. Mitunter sind die Kerncontouren von einer dünnen, wenig ausgeprägten Linie begrenzt, an welcher stellenweise kleine Verdickungen wahrgenommen werden, die, wie auch die den Kern umgebende Linie, dunkel gefärbt sind (Hämatoxylin). Die erwähnten Verdickungen pflanzen sich in manchen Fällen auf einer grösseren oder kleineren Strecke in die Kernsubstanz fort und vereinigen sich bier zuweilen mit einer Chromatinscholle. Häufiger jedoch bilden diese Verdickungen eine kleine Zahl sehr kurzer Vorsprünge an dem Innentheile der peripheren Linie; in der Kernsubstanz selbst ist eine spärliche Menge von verschieden grossen und unregelmässig geformten Chromatinschollen eingelagert. In seltenen Fällen kann man eine kreuzförmige Anordnung der Chromatinstrablen beobachten, welche mit der centralen Scholle theilweise zusammenhängen. Diese Kerne unterscheiden sich jedoch von denjenigen der Erythroblasten: 1) durch ihre unregelmässigen Contouren, 2) durch blasse Färbung, 3) durch stets geringfügige Menge von Chromatinstrahlen. In der Mehrzahl der Fälle ist in der Anordnung der Chromatinverdickungen und Schollen keine Regelmässigkeit und Ordnung wahrunehmen; dabei ist ihre Zahl stets eine unbedeutende im Vergleiche zur Grösse des Kernes. Durch diesen Umstand wird auch die verhältnissmässig blasse Färbung der Leukocytenkerne bedingt. Uebrigens färben sich die Kerne der jüngeren Formen etwas dunkler, was von der geringeren Grösse der Kerne in gegebenem Falle und, folglich, von der dichteren Anordnung der Chromatinschollen auf einem kleineren Gebiete abhängt.

Der Leib der Leukoblasten und Leukocyten besitzt nicht so scharfe und bestimmte Umrisse, wie wir das bei den Erythroblasten gesehen haben. Ihr Protoplasma ist nicht homogen, glänzt nicht, sondern erscheint trübe, matt.

Die weitere Entwickelung der Leukoblasten geschieht in umgekehrter Ordnung im Vergleiche zu den Erythroblasten. Dort 
Einige Bemerkungen zur Morphologie und Entwickelung etc. 175

haben wir die allmähliche Verkleinerung der ganzen Zelle und des Kernes bis zum gänzlichen Verschwinden des letzteren beobachtet; hier wächst, im Gegentheil, der Kern, vergrössert sich bis zu bestimmten Grenzen, zugleich vergrössert sich auch die ganze Zelle. Je nach dem Heranwachsen färbt sich der Kern allmählich blasser, da sich die Menge der Chromatinsubstanz dabei scheinbar nicht vergrössert.

Mit dem weiteren Verlaufe der Entwickelung ändert der Kern auch seine Form. Er erhält zunächst an der Peripherie eine mehr oder weniger tiefe Einbuchtung, welche später noch schärfer ausgeprägt ist. Der Kern zieht sich aus, wird verlängert, wird wurstförmig und gebogen. Indem er sich verlängert, verjüngt und noch mehr krümmt, erhält er höchst mannigfaltige Umrisse, die für die Leukocytenkerne so charakteristisch sind. Auf der Taf. VIII, Fig. 11, 12, 13, sind die Elemente eines M a l p i g h i 'schen Körperchens abgebildet, welche die allmähliche Entwickelung von den jüngsten Formen (die Zellen der centralen Zone des M a I pighi 'schen Körperchens, welche unmittelbar an der Peripherie des centralen Gefässes angeordnet sind) bis zu den reiferen (die Zellen der mittleren und der peripheren Zone) präsentiren. Die spätesten Entwickelungsformen werden im benachbarten Gewebe beobachtet.

Die Leukoblasten und Leukocyten vermehren sich durch Mitose. Dafür sprechen einerseits auch die vielen unter jungen Elementen vorkommenden Mitosen (die Follikel der Lymphdrüsen, die M a l p i g h i'schen Körperchen), anderseits - Mitosen höchst charakteristischer granulirter Leukocyten (s. Taf. VIII, Fig. 15), die zuweilen angetroffen werden.

Somit sind die Unterscheidungsmerkmale der Erythro- und Leukoblasten folgende:

Erythroblasten:

1. Der Kern besitzt eine runde oder ovale Form.

2. Der Kern ist reich an Chromatin und färbt sich daher intensiv.

3. Das Kernchromatin hat eine charakteristische Anordnung in Form von radiären Strahlen, zuweilen netzförmig.
Le uk oblasten:

Der Kern ist von unregelmässiger Form.

Der Kern ist weniger reich an Chromatin und färbt sich daher auch weniger intensiv.

Die Anordnung des Chromatins ist nicht so charakteristisch, häufig sogar fehlt jegliche Ordnung. 


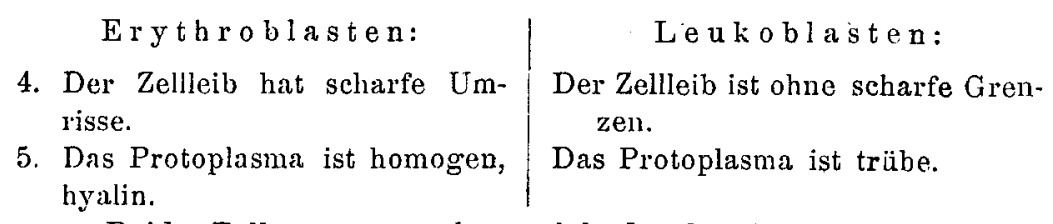

Beide Zellarten vermebren sich durch mitotische Theilung.

Auf die Beschreibung der bei den einzelnen untersuchten Thierarten gewonnenen Specialbefunde soll hier nicht näher eingegangen werden. Das was von diesen Befunden nicht bereits im Vorstehenden mitgetheilt wurde, wird man in der folgenden Zusammenstelling der Resultate finden.

\section{Ergebnisse.}

1. Die stäbchenförmige Körnung ist nicht nur den Leıkocyten des Vogelblutes eigen, soudern kommt auch in den Leukocyten einiger Säugethiere (Katze) vor.

2. Im Gegentheil zu den gewöhnlichen sphärischen Körnern weisen die stäbchenförmigen eine gewisse Differenzirung der sie aufbanenden Substanz auf, was sich durch das Auftreten von dunklen (intensiv tingiblen) und hellen (nicht tingiblen) pünktchenförmigen Gebilden in den Stäbchen kennzeichnet. Diese Eigenheit besitzen übrigens nur die Stäbchenkörner des Vogelblutes.

3. Sowohl die Leukocyten als auch die Erythrocyten erleiden, ehe sie vollkommen reif werden, eine Reihe von successiven Umwandlungen der ursprünglichen Bildungszellen, welche sich durch specifische Eigenheiten für jede Art der genannten Körperchen auszeichnen.

4. Die Verwandlung der Erythroblasten in definitive kernlose Körperchen der Säugethiere geschieht durch den intracellulären $\mathrm{Z} \mathrm{e} \mathrm{r} \mathrm{f} \mathrm{a} 11$ des Kernes, welcher zunächst Veränderungen in seiner Structur erleidet und sich progressiv verkleinert. Die Partikelchen des zerfallenen Kernes verschwinden, werden so zu sagen resorbirt, aufgelöst. In anderen Fällen kann der Kern scheinbar durch allmähliche Atrophie verschwinden, welche sich durch progressive Abnahme des Volumens, Structuränderung und durch allmählichen Schwund der tingiblen Kernsubstanz (ohne vorläufigen Zerfall desselben in Theile) kundgiebt. 
5. Die Entwickelung und Verwandlung der Erythroblasten geschieht in den blutbildenden Organen. Von ibuen steht in erster Reihe das Knochenmark, welches bei den Säugethieren diese Function während des ganzen Lebens des Organismus bewahrt und stets eine reichliche Menge von Entwicklungsformen der rothen Blutkörperchen enthält.

6. Die Milz der Süugethiere ist ebenfalls an der Bildung von rotheu Blutkörperchen betheiligt, wobei die blutbildende Thätigkeit des genannten Organes auch während des Extrauterinlebens, sogar bei ganz alten Thieren conservirt bleibt. Aber während bei den Embryonen und auch während einer bestimmten Periode nach der Geburt des Thieres in der Mil\% eine lebhafte Neubildung einer grossen Menge vou farbigen Elementen stattfindet, wird mit dem Alter des Individuums die Function der Milz in dieser Hinsicht etwas schwächer, wie das aus dem verhältnissmässig geringen Gehalte an Entwickelungsformen bei älteren Thieren $\mathrm{zu}$ ersehen ist. Sonach besteht im späteren Alter nur ein quantitativer Unterschied zwischen dem Knochenmark und der Milz. Jedoch kann die blutbildende Function der letzteren unter gewissen Verhältnissen wieder erhöht werden. So z. B. wird eine Anläufung einer grossen Menge verschiedener Erythroblastenformen zur Zeit der Schwangerschaft und bei mangelhafter Thätigkeit des Knochenmarkes (Fettmark) beobachtet.

7. Die Entwickelung und die Verwandlung der Erythroblasten geschieht in der Milzp u l p a selbst. Die Malpighischen Körperchen sind an diesem Vorgange gar nicht betheiligt. Die späteren Entwickelungsformen der Erythroblasten kommen auch in den Venen der Milzpulpa vor, aber weit seltener und in viel geringerer Menge.

8. Die L y m p h $\mathrm{d}$ ii s e $\mathrm{n}$ sind weder bei den jungen noch len alten Thieren an der Bildung der rothen Blutkörperchen, wenigstens unter normalen Verhältnissen, betheiligt. Jedocb auch in ihnen beobachtet man zuweilen unter gewissen Umständen höchst spärliche Erythroblasten, wie wir das bei schwangeren Meerschweinchen und bei erwachsenen Hunden mit stark entwickeltem Fettmarke gesehen haben.

9. Bei den Vögeln haben die Bildungszellen der rothen Blutkörperchen denselben Charakter, wie bei den Säugethieren. 
10. Im Knochenmark, in der Milz und den Lymphdrüsen findet ausser der Neubildung von Blutkörperchen anch ein Untergang derselben statt. Letzterer wird durch Gigantophagocyten bewirkt.

Meinem hochverehrten Lehrer, Herrn Professor $\mathrm{K}$ ults chitzky, sage ich für die gitige Unterstützung bei dieser Arbeit meinen wärmsten Dank.

\section{Erklärung der Abbildungen auf Tafel VIII u. IX.}

Alle Abbildungen sind mit Hülfe des Zeichenapparates nach $\mathrm{Abb}$ é neuester Construktion ( $\mathrm{Z}$ e is s) ausgeführt; Mikroskop von Reichert.

\section{Tafel VIII.}

Fig. 1, 2 und 3. Leukocyten aus dem Blute eines Hühnchens. Die verschiedenartigen stiibchenförmigen Körner sind mit einem hellen centralen Punkte versehen. Die Punkte sind dunkelviolett gefärbt (mit bräunlicher Nüance). Auf Fig. 1 liegt neben dem Leukocyten ein rothes Blutkörperchen. Der Leukocytenkern ist voluminös, hat in der Mitte eine Einbuchtung, ist schwach grünlich gefärbt; der Leukocytenleib ist nur theilweise conservirt. Auf Fig. 2 nimmt den grössten Theil des Körperchens ein schwach grünlich gefärbter Kern ein, das Protoplasma des Leukocyten ist nur an einer Stelle an der Kernperipherie (als Sichel) erhalten geblieben. Auf Fig. 3 sind das Protoplasma und der Leukocytenkern gut erhalten - der Kern ist rundlich, voluminös, das Protoplasma umgiebt denselben als regelmässiger Reif.

Oel-Immersion 1/12 (18) + Compensations-Ocular Nr. 12; Färbung mit Ehrlich's neutraler Lösung (Orange+saures Fuchsin + Methylgrün).

Fig. 4. Ein Häufchen Leukocytenkörner aus dem Blute eines anderen Hühnchens. Die Körner sind spindelförmig, sie sind deutlich violett gefürbt, haben einen centralen Punkt, welcher gleich intensi violett gefärbt ist. Die Körner sind neben den anliegenden rothen Blutkörperchen dicht angehäuft. Das Leuko: cytenprotoplasma ist zerstört, die Spuren des Kernes sind 
Einige Bemerkungen zur Morphologie und Entwickelung etc. 179

nicht abgebildet, um die Deutlichkeit der Zeichnung zu erhöhen.

Oel-Imm. 1/12 (18) + Comp.-Oc. Nr. 12; Färbung mit Ehrlich's neutraler Lösung (saures Fuchsin + Methylenblau).

Fig. 5. Ein Leukocyt aus dem Blute eines dritten Hühnchens. Die Contouren desselben sind deutlich ausgeprägt; zwei Kerne sind schwach grünlich gefärbt. Die Körner sind spindelförmig, violett tingirt, besitzen einen centralen dunkel-violetten Punkt.

Oel-Imm. $1 / 12(18)+$ Comp.-Oc. Nr. 12; Färbung mit Spilli ng's neutraler Mischung (saur. Fuchsin + Methylgrün).

Fig. 6 und 7. Leukocyten mit Körnern von runder Form aus dem Blute eines Hühnchens. Auf Fig. 6 ist der Leukocytenkern gut conservirt, der Leib nur theilweise. Auf Fig. 7 sind die Contouren des Körperchens deutlich ausgeprägt, gleich wie auch seine drei Kerne, die als hellere Flecken erscheinen.

Oel-Imm. 1/12 (18)+Comp.-Oc. Nr. 12; Färbung mit Ehrlich's neutraler Lösung (Orange + saures Fuchsin + Methylgrün).

Fig. 8, 9 und 10. Leukocyten aus dem Blute eines Hühnchens. Kerne derselben intensiv durch Hämatoxylin gefärbt, die Bezirke des Protoplasmas zwischen den Körnern etwas schwächer durch Hämatoxylin oder durch das Gemiseh des letzteren mit Eosin, die spindelförmigen Körner ungefärbt, blass ${ }^{1}$ ).

Oel-Imm. 1/12 (18) + Comp.-Oc. Nr. 12; Eosin-Hämatoxylin nach Ehrlich.

Fig. 11, 12 und 13 zeigen die allmähliche Entwickelung der Elemente der Malpighi'schen Körperchen in der Milz eines erwachsenen Hundes. Auf Fig. 11 Elemente der centralen Schicht des Malpighi'schen Körperchens, gelegen in ummittelbarer Nachbarschaft des centralen Gefässes, von dem ein Theil der Wandung abgebildet ist. Auf Fig. 12 Elemente der mittleren Schicht desselben Körperchens. Auf Fig. 13 Elemente der peripheren Schicht.

Oel-Immersion 1/12 (18) + Oc. Nr. 4.

Fig. 14. Farblose Blutkörperchen und ein Erythroblast (a), gelegen im weiten Lumen der Vene. Prïparat der Milz von demselben Hunde.

Oel-Imm. $1 / 12(18)+$ Oc. Nr. 4.

Fig. 15. Mitotische Theilung eines granulirten Leukocyten aus dem Knochenmark eines Hundes.

Oel-Imm. ${ }^{1 / 12}(18)+$ Oc. Nr. 3 (Z eiss).

Fig. 16. Mitotische Theilung von Erythroblasten aus der Milz eines erwachsenen Hundes.

Oel-Imm. $1 / 12(18)+$ Oc. Nr. 4.

1) Der Unterzeichnete verfehlt nicht darauf hinzuweisen, dass die spindeltörmigen Körperchen der Figuren 1, 3, 4, 5, 8, 9 u. 10 stark an parasitäre Bildungen erinnern.

Waldeyer. 
Tafel IX.

Fig. 1. Verschiedene Entwickelungsstadien der Erythroblasten in der Milz einer erwachsenen (schwangeren) Hündin. Die successive Reihe der Entwickelungsformen ist durch die Buchstaben des Alphabets bezeichnet.

Oel-Imm. $1 / 12(18)+$ Oc. Nr. 4.

Fig. 2. Erythroblasten und Leukocyten aus dem Knochenmark eines Meerschweinchens.

Oel-Imm. $1 / 12(18)+$ Oc. Nr. 2.

Fig. 3. Erythroblasten aus der Milz desselben Meerschweinchens. Oel-Imm. $1 / 12$ (18) + Oc. Nr. 2.

Fig. 4. Erythroblasten uud Leukocyten aus dem Knochenmark einer Taube. Der successive Entwickelungsgang ist durch Buchstaben angedeutet.

Oel-Imm. $1 / 12(18)+$ Oc. Nr. 3 (Zeiss).

Fig. 5. Verschiedenartig auso'ezogene und gekrümmte Erythroblastenkerne aus der Kaninchenmilz.

Oel-Imm. 1/12 (18) + Oe. Nr. 3 (Z e is s).

Fig. 6. Durchgang eines Erythroblasten durch die Wandung eines Blutgefässes. Kaninchenmilz.

Oel-Imm. ${ }^{1 / 12}(18)+$ Oc. Nr. 3 (Z e iss).

Fig. 7, 8, 9, 10 und 11. Gigantophagocyten aús der Meerschweinchenmilz. Alle Riesenzellen enthaiten in ihrem Protoplasma tropfenförmige Gebilde, die durch Hämatoxylin intensiv gefärbt sind. Diese Bildungen besitzen vorzugsweise eine regelmässige runde Form, seltener ist ihre Form mehr oder minder unregelmässig. Oel-Imm. 1/12 (18) + Oc. Nr. 4.

Fig. 12. Phagocyt aus dem Malpighi'schen Körperchen "der Milz eines anderen Meersehweinchens. Dreifache Färbung (Rubin + Hämatoxylin + Helianthin). Ausser den tropfenförmigen durch Rubin rosa gefärbten Gebilden ist in Protoplasma der Riesenzelle ein fremdes Zellelement eingelagert. Letzteres liegt scheinbar innerhalb einer grossen Vacuole.

Oel-Imm. $1 / 12$ (18) + Oc. Nr. 3 (Z e is s).

Für alle Riesenzellen ein und dieselben Bezeichnungen:

a) Die Kerne der Riesenzellen selbst.

b) Die Kerne der von den Phag'ocyten aufgenommenen fremden Elemente; diese Kerne zeigen bedeutende Structurveränderungen in Zusammenhang mit dem Processe ibrer Zerstörung.

c) Fremde Elemente, die scheinbar in Vacuolen innerhalb der Gigantophagocyten liegen. Auf Fig. 10 präsentirt sich die Zelle als eine regelmässige, scharf contourirte Scheibe mit zwei grossen Chromatintropfen (Rest des zerfallenen Kernes); um die Scheibe befindet sich ein deutlich bemerkbarer, vollkommen ungefärbter ringförmiger Streifen. Dasselbe auf Fig. 7 nur mit dem Unterschiede, dass hier der farblose 
Einige Bemerkungen zur Morphologie und Entwickelung etc. 181

Streifen nur einen Theil der Peripherie des fremden Elements als schmale Sichel umgiebt.

d) Fremde Zellen innerhalb der Phagocyten; vom Protoplasma dieser aufgenommenen Elemente ist nur ein heller Flecken übrig geblieben; in letzterem sind tropfenförmige Chromatinschollen (Kernrest) eingelagert. Auf Fig. 7 sind die genannten Chromatintropfen mit einem centralen hellen Punkte versehen.

Fig. 13 präsentirt einige Formen von tropfenförmigen Einschlüssen im Protoplasma der Gigantophagocyten. Diese Einschlüsse sind mit 1-2 hellen Punkten versehen, welche auf dem dunklen, durch Hämatoxylin intensiv schwarz gefärbten Tropfen scharf hervortreten; häufig nehmen diese Punkte eine andere Färbung an (Orange, Aurantia).

Oel-Imm. $1 / 12(18)+$ Oc. Nr. 4.

Fig. 14 und 15. Zellelemente, deren Kerne zerfallen und verschieden verändert erscheinen. Aehnliche Elemente werden sowohl innerhalb der Phagocyten, als auch ausserhalb derselben als einzelne Exemplare zwischen den Zellen der Malpighi'schen Körperchen und der Milzpulpa beobachtet. Meerschweinchenmilz. Oel-Imm. 1/12 (18) + Oc. Nr. 4.

Sämmtliche Abbildungen sind vom Autor nach der Natur gezeichnet und in Farben aquarellirt worden.

\section{Die Entwicklung der äusseren Form des Forellen-Embryo.}

Von

Fr. Kopseh.

Assistent am I. anatomischen Institut zu Berlin.

Hierzu Tafel $\mathrm{X}$ und $\mathrm{XI}$.

\section{Einleitung.}

Diese Arbeit ist hervorgegangen aus der von Herrn $\mathrm{H}$. V i rchow angeregten und mit den Herren Sobotta und Ziegenh a g e n sowie dem Verfasser angestellten Untersuchung über die Entwicklung der Knochenfische, insbesondere derjenigen der Forelle.

Während durch die bei dem gemeinschaftlichen Unternehmen vorgenommene Arbeitstheilung, welche den einzelnen volle Freiheit 